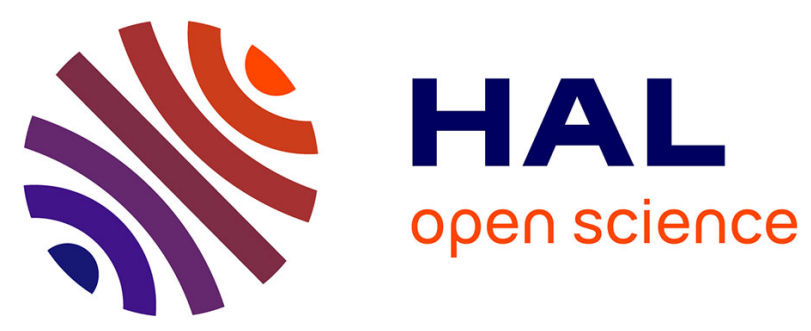

\title{
An effective combination reaction involved with sputtered and selenized Sb precursors for efficient Sb2Se3 thin film solar cells
}

Y.-D. Luo, R. Tang, S. Chen, J.-G. Hu, Y.-K. Liu, Y.-F. Li, X.-S. Liu, Z.-H. Zheng, Z.-H. Su, X.-F. Ma, et al.

\section{To cite this version:}

Y.-D. Luo, R. Tang, S. Chen, J.-G. Hu, Y.-K. Liu, et al.. An effective combination reaction involved with sputtered and selenized Sb precursors for efficient Sb2Se3 thin film solar cells. Chemical Engineering Journal, 2020, 393, pp.124599. 10.1016/j.cej.2020.124599 . hal-02536592

HAL Id: hal-02536592

https://hal-univ-rennes1.archives-ouvertes.fr/hal-02536592

Submitted on 4 May 2020

HAL is a multi-disciplinary open access archive for the deposit and dissemination of scientific research documents, whether they are published or not. The documents may come from teaching and research institutions in France or abroad, or from public or private research centers.
L'archive ouverte pluridisciplinaire HAL, est destinée au dépôt et à la diffusion de documents scientifiques de niveau recherche, publiés ou non, émanant des établissements d'enseignement et de recherche français ou étrangers, des laboratoires publics ou privés. 


\section{An effective combination reaction involved with sputtered and}

\section{selenized $\mathrm{Sb}$ precursors for efficient $\mathrm{Sb}_{2} \mathrm{Se}_{3}$ thin film solar cells}

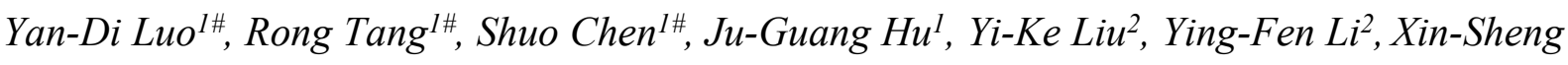
Liu $^{3}$, Zhuang-Hao Zheng ${ }^{1}$, Zheng-Hua Su${ }^{1}$, Xiu-Fang Ma ${ }^{1}$, Ping Fan ${ }^{1}$, Xiang-Hua Zhang ${ }^{4}$, Hong-Li Ma ${ }^{4}$,Zhi-Gang Chen ${ }^{5}$, Guang-Xing Liang ${ }^{\text {* }}$

1 Shenzhen Key Laboratory of Advanced Thin Films and Applications, Key Laboratory of Optoelectronic Devices and Systems of Ministry of Education and Guangdong Province, College of Physics and Optoelectronic Engineering, Shenzhen University, Shenzhen 518060, P. R. China

${ }^{2}$ School of Material and Metallurgical Engineering, Guizhou Institute of Technology, Guiyang 550003, P. R. China

${ }^{3}$ Key Laboratory for Special Functional Materials of Ministry of Education, Henan University, Kaifeng 475004, P. R. China

${ }^{4}$ Univ Rennes, CNRS, ISCR (Institut des Sciences Chimiques de Rennes) UMR6226, Rennes F35000, France

5 Centre for Future Materials, University of Southern Queensland, Springfield Central, Brisbane, Queensland, 4300, Australia

\# Yan-Di Luo, Rong Tang, and Shuo Chen contributed equally.

*Corresponding author: Email: lgx@zu.edu.cn (Prof. Liang)

Keywords: $\mathrm{Sb}_{2} \mathrm{Se}_{3}$ solar cell; Magnetron sputtering; Selenization; Combination reaction; DFT calculations

Abstract: Sputtering followed by post annealing is extensively used for fabrication of copper indium gallium selenide (CIGS), copper zinc tin sulfide (CZTS) and copper zinc tin sulfur selenide (CZTSSe) thin film solar cells. In this work, $\mathrm{Sb}_{2} \mathrm{Se}_{3}$ as an emerging alternative absorber was fabricated by an effective combination reaction of annealing sputtered Sb metallic precursors under Se vapor. Self-assembled growth of $\mathrm{Sb}_{2} \mathrm{Se}_{3}$ thin films consist of large grains that across the whole films have been successfully fulfilled via this combination reaction. 
$\mathrm{Sb}_{2} \mathrm{Se}_{3}$ thin films with desired orientation, stoichiometric composition and high-quality $\mathrm{Sb}_{2} \mathrm{Se}_{3} / \mathrm{CdS}$ heterojunction could be achieved once a proper selenization scenario was employed. Further, by selecting $\mathrm{Sb}$ films as precursors, the thickness of interfacial $\mathrm{MoSe}_{2}$ located at the back-contact region can be well controlled, leading to a significant enhancement in fill factor (FF) of the devices. This is in good accordance with our DFT simulation results which demonstrated Se vapor would be prone to react with the Sb lattice thermodynamically and thus limiting the thickness of the $\mathrm{MoSe}_{2}$ layer. Finally, a champion $\mathrm{Sb}_{2} \mathrm{Se}_{3}$ thin film solar cell with power conversion efficiency of $6.15 \%$ was achieved, which represents the highest efficiency of sputtered $\mathrm{Sb}_{2} \mathrm{Se}_{3}$ solar cells.

\section{Introduction}

Thin film photovoltaics has been developed rapidly during the last decade as the power conversion efficiencies (PCE) of state-of-the-art thin film solar cells have already caught up with that of crystalline silicon solar cells. ${ }^{[1-3]}$ Cadmium telluride (CdTe) is one of the most welldeveloped thin film technologies due to its high device efficiency and low cost. However, the toxicity of $\mathrm{Cd}$ might hinder its further application since trends are moving to abundant and nontoxic materials for thin film photovoltaics. Antimony selenide $\left(\mathrm{Sb}_{2} \mathrm{Se}_{3}\right)$ is regarded as an emerging non-toxic alternative absorber material to $\mathrm{CdTe}$. $\mathrm{Sb}_{2} \mathrm{Se}_{3}$ is also a binary compound with only one stable phase. Further, it possesses excellent optoelectronic properties such as ideal optical bandgap $(1.2 \mathrm{eV})$, high absorption coefficient $\left(>10^{5} \mathrm{~cm}^{-1}\right)$ and decent carrier mobility $\left(\sim 10 \mathrm{~cm}^{2} \mathrm{~V}^{-1} \mathrm{~s}^{-1}\right) \cdot{ }^{[4-6]}$ Moreover, the elemental compositions of $\mathrm{Sb}$ and Se, are both nontoxic and earth-abundant, suggesting a bright future of $\mathrm{Sb}_{2} \mathrm{Se}_{3}$ photovoltaic for high-efficiency performance and low-cost manufacturing.

$\mathrm{Sb}_{2} \mathrm{Se}_{3}$ crystals are composed of one-dimensional $\left(\mathrm{Sb}_{4} \mathrm{Se}_{6}\right)_{\mathrm{n}}$ ribbons stacking vertically on the substrate via strong covalent Sb-Se bonds whilst in the [010] and [100] directions the ribbons are bonded together by weak van der Waals forces. ${ }^{[7]}$ Photogenerated carriers are 
believed to be able to travel along the one-dimensional vertically oriented ribbons effectively. On the other hand, carrier transport would be much more difficult in the horizontal directions such as [010] and [100] since the carriers would have to hop across the barriers between ribbons. Therefore, crystal orientation has become an essential issue in high-efficiency $\mathrm{Sb}_{2} \mathrm{Se}_{3}$ thin film solar cell fabrication. Various thin film deposition techniques have been applied to fabricate highly optimized $\mathrm{Sb}_{2} \mathrm{Se}_{3}$ absorber layer, such as solution method, ${ }^{[8-11]}$ thermal evaporation, ${ }^{[7,12-}$ 15] vapor transport deposition (VTD), ${ }^{[16-18]}$ close spaced sublimation $(\mathrm{CSS})^{[6,}$ 19,20] and sputtering. ${ }^{[21,22]}$ To date, the highest $\mathrm{PCE}$ of $\mathrm{Sb}_{2} \mathrm{Se}_{3}$ thin film solar cells in the substrate and superstrate configurations are $9.2 \%{ }^{[19]}$ and $7.6 \%,{ }^{[16]}$ respectively, where CSS and VTD methods were utilized to tune the crystal orientation and crystallinity of the $\mathrm{Sb}_{2} \mathrm{Se}_{3}$ absorber layer precisely. Interface engineering was also conducted in $\mathrm{Sb}_{2} \mathrm{Se}_{3}$ devices as attempts have been made by introducing additional buffer layers to passivate defects at the heterojunction. ${ }^{[9,18,23]}$ However, it is widely accepted that a perfected light absorber layer still plays the most important role in $\mathrm{Sb}_{2} \mathrm{Se}_{3}$ photovoltaics.

Among the above-mentioned deposition techniques, magnetron sputtering is a wellestablished approach that has been extensively utilized in preparation of conventional efficient thin film solar cells such as copper indium gallium selenide (CIGS), copper zinc tin sulfide (CZTS) and copper zinc tin sulfur selenide (CZTSSe). ${ }^{[24-26]}$ Unlike other deposition techniques that could possibly lead to impurity introduction and material waste, magnetron sputtering has the advantages of precise composition control, excellent uniformity and simple experimental setup. So far, most of $\mathrm{Sb}_{2} \mathrm{Se}_{3}$ devices with top PCEs were fabricated by thermal evaporation, VTD and CSS techniques. Only a few efforts have been put on the investigation of magnetron sputtered $\mathrm{Sb}_{2} \mathrm{Se}_{3}$ thin films, thus further research would enable a bench mark to be established and provides a bright future to improve the overall performance of $\mathrm{Sb}_{2} \mathrm{Se}_{3}$ thin film solar cells. Recently, we have reported a $\mathrm{Sb}_{2} \mathrm{Se}_{3}$ thin film solar cell with PCE of $6.06 \%$ fabricated via magnetron sputtering followed by a post-selenization process. ${ }^{[27]}$ [211]-oriented $\mathrm{Sb}_{2} \mathrm{Se}_{3}$ thin 
films with decent crystallinity were successfully prepared under an optimized selenization scenario after sputtered from a $\mathrm{Sb}_{2} \mathrm{Se}_{3}$ compound target. The final device presents a competitive short circuit current $\left(J_{S C}\right)$ of $25.91 \mathrm{~mA} / \mathrm{cm}^{2}$ and open circuit voltage $\left(V_{O C}\right)$ of $494 \mathrm{mV}$. However, compared to other highly efficient $\mathrm{Sb}_{2} \mathrm{Se}_{3}$ solar cells, the fill factor (FF) of this device is relatively poor with a value of $47.7 \%$.

Post-annealing treatment of metallic precursors is an effective approach to fabricate efficient chalcogenide thin film solar cells such as CIGS, CZTSe and CZTSSe. ${ }^{[28-30]}$ The method enjoys the merit of accurate control of morphology and composition simultaneously. Enhanced crystallinity and larger grains of the absorbing thin films could be achieved by careful optimization of the annealing process. In this work, a combination reaction was utilized by annealing sputtered $\mathrm{Sb}$ metallic precursors under Se atmosphere to produce crystallized $\mathrm{Sb}_{2} \mathrm{Se}_{3}$. In order to prepare $\mathrm{Sb}_{2} \mathrm{Se}_{3}$ thin films with desired orientation and crystallinity, the selenization process was thoroughly adjusted and investigated. Self-assembled growth of $\mathrm{Sb}_{2} \mathrm{Se}_{3}$ thin films consist of large grains whose sizes are equivalent to the thickness of the films has been successfully fulfilled via this combination reaction. The method has distinct advantages over the one in our last report where amorphous $\mathrm{Sb}_{2} \mathrm{Se}_{3}$ thin films were sputtered and selenized to produce the crystallized absorber layers. Firstly, selenization of the Sb metallic precursor would facilitate delicate control of the thin film key parameters such as orientation, chemical composition and crystallinity etc. Second, rather than using an expensive $\mathrm{Sb}_{2} \mathrm{Se}_{3}$ alloy sputtering target, a more economical Sb metallic target was chosen for this work. Moreover, the thickness of $\mathrm{MoSe}_{2}$ interfacial layer at the back-contact region could be substantially reduced, leading to a significant recombination inhibition at the $\mathrm{Sb}_{2} \mathrm{Se}_{3} / \mathrm{MoSe}_{2}$ interface thus a great FF improvement. Finally, a champion $\mathrm{Sb}_{2} \mathrm{Se}_{3}$ thin film solar cell with PCE of $6.15 \%$ was achieved, which represents the highest efficiency of sputtered $\mathrm{Sb}_{2} \mathrm{Se}_{3}$ solar cells.

\section{Experimental Section}




\section{Deposition of $\mathrm{Sb}_{2} \mathrm{Se}_{3}$ thin film}

Sb metallic precursors were deposited using a radiofrequency (RF) magnetron sputtering deposition system. High-purity Sb powder (>99.99\%) purchased from HZAM (Beijing, China) was ball milled for 8 hours at a speed of $300 \mathrm{rpm} / \mathrm{min}$ and then sintered to prepare a dense $\mathrm{Sb}$ sputtering target (diameter of $60 \mathrm{~mm}$ and thickness of $2 \mathrm{~mm}$ ) by Labox-325 SPS with a fixed pressure of $30 \mathrm{KN}$ and temperature of $350{ }^{\circ} \mathrm{C}$. Prior to sputtering deposition, Mo-coated glass substrates were subsequently cleaned in an ultrasonic bath using detergent, ethanol and deionized water. The background pressure of the sputtering vacuum chamber was evacuated below $7.0 \times 10^{-4} \mathrm{~Pa}$ before the sputtering procedure commenced. Ar with high purity $(>99.999 \%)$ was introduced into the sputtering chamber at a flow rate of $40 \mathrm{sccm}$. The working pressure and sputtering power were kept at $0.5 \mathrm{~Pa}$ and $30 \mathrm{~W}$ during the sputtering process, respectively. The sputtering duration was fixed at 60 min without additional in-situ heat treatment to obtain $\mathrm{Sb}$ metallic precursor with thickness of approximately $600 \mathrm{~nm}$. Post-selenization procedures were subsequently carried out to prepare crystallized $\mathrm{Sb}_{2} \mathrm{Se}_{3}$ thin films (the details of the selenization process will be discussed later).

\section{Device fabrication}

Cadmium sulfide (CdS) buffer layer was deposited onto the crystallized $\mathrm{Sb}_{2} \mathrm{Se}_{3}$ thin films using chemical bath deposition (CBD) once the selenization process was finished. Cadmium sulfate $\left(3 \mathrm{CdSO}_{4} \cdot 8 \mathrm{H}_{2} \mathrm{O}\right)$ powder, thiourea powder and ammonium hydroxide aqueous solution $(28 \%)$ were purchased from Aladdin (Shanghai, China). $\mathrm{CdSO}_{4}$ aqueous solution $(0.015 \mathrm{M})$, thiourea aqueous solution $(0.75 \mathrm{M})$ and ammonium hydroxide aqueous solution were subsequently added to deionized water. The substrates were soaked into the mixed solution which was then placed in an $80{ }^{\circ} \mathrm{C}$ water bath under continuous stirring for $9 \mathrm{~min}$. The substrates were rinsed with deionized water and dried in an oven. Indium tin oxide (ITO) thin film was then magnetron sputtered as a window layer. The device surface was scribed into small squares with identical area by knife and Ag electrodes were deposited onto the ITO surface via thermal evaporation 
to form metallic contact (active area of each device $=0.15 \mathrm{~cm}^{2}$ ). A substrate configuration of $\mathrm{Mo} / \mathrm{Sb}_{2} \mathrm{Se}_{3} / \mathrm{CdS} / \mathrm{ITO} / \mathrm{Ag}$ was assembled for our $\mathrm{Sb}_{2} \mathrm{Se}_{3}$ solar cells. The schematic diagram of the whole process of the $\mathrm{Sb}_{2} \mathrm{Se}_{3}$ thin film solar cell fabrication is illustrated in Figure 1.

\section{Characterization of the $\mathrm{Sb}_{2} \mathrm{Se}_{3}$ films and devices}

Surface and cross-sectional microstructures of the $\mathrm{Sb}_{2} \mathrm{Se}_{3}$ films were characterized using a scanning electron microscope (SEM, SUPRA 55). Crystal orientations of the $\mathrm{Sb}_{2} \mathrm{Se}_{3}$ films were studied by X-ray diffraction (XRD, Ultima-iv, $C u K_{\alpha}$ radiation under operation conditions of 40 $\mathrm{kV}$ and $40 \mathrm{~mA}$ from $10^{\circ}$ to $60^{\circ}$ ). Chemical compositions of the films were analyzed using an energy dispersive X-ray spectroscope (EDS, BRUKER QUANTAX 200) equipped with the SEM. The current density-voltage $(J-V)$ curves of the $\mathrm{Sb}_{2} \mathrm{Se}_{3}$ devices were measured under 100 $\mathrm{mW} / \mathrm{cm}^{2} \mathrm{AM} 1.5 \mathrm{G}$ light illumination using a class AAA solar simulator at room temperature. The external quantum efficiency (EQE) spectra were measured using a Zolix SCS101 system and a Keithley 2400 source meter. Transmission electron microscope (TEM) images were taken using a FEI Titan Cubed Themis G2 300 microscope. The sample for TEM imaging was prepared by ablating the thin film device using focused ion beam (FIB, FEI Scios). Temperature-dependent $V_{O C}$ measurements were carried out using a Lakeshore 325 temperature controller and the temperatures were swept from $350 \mathrm{~K}$ to $120 \mathrm{~K}$ in a step of $30 \mathrm{~K}$. During the measurements, the devices were mounted inside a Janis VPF-100 cryostat and cooled with liquid nitrogen. Capacitance-voltage $(C-V)$ measurements were conducted at AC amplitude of $30 \mathrm{mV}$ and frequency of $10 \mathrm{kHz}$ under a dark condition at room temperature. The DC bias voltage during the $C$ - $V$ measurements was applied from $-1 \mathrm{~V}$ to $0.3 \mathrm{~V}$. Drive level capacitance profiling (DLCP) measurements were performed with an AC amplitude from $20 \mathrm{mV}$ to $140 \mathrm{mV}$ and a DC bias voltage from $-0.2 \mathrm{~V}$ to $0.2 \mathrm{~V}$. Temperature-dependent capacitance-frequency $(C$ $f-T$ ) measurements were carried out within the frequency range of $1 \mathrm{kHz}$ to $10 \mathrm{MHz}$ using the same cryostat and cooling system as mentioned above.

\section{Density functional theory (DFT) calculation methods}


DFT calculations were carried out using VASP5.3, ${ }^{[31,32]}$ with the all-electron projector augmented wave (PAW) method. ${ }^{[33,34]}$ The exchange-correlation effects were described by the generalized gradient approximation in form of Perdew-Burke-Ernzerh. ${ }^{[35]}$ The wave functions were expanded in a basis of plane waves with a kinetic energy cutoff of $520 \mathrm{eV}$ and a density cutoff of $900 \mathrm{eV}$. Three-dimensional 54 -atom periodic supercells with $(3 \times 3 \times 3)$ and $(3 \times 3 \times 1)$ unit cells were utilized for simulations of the bulk Mo and Sb systems, respectively. The corresponding Brillouin zone was sampled by $(3 \times 3 \times 3)$ and $(2 \times 2 \times 2)$ Gamma-centered Monkhorst-Pack grid meshes for the bulk Mo and Sb, respectively. ${ }^{[36-38]}$ Equilibrium cell volumes and all internal atomic positions of the supercells were fully relaxed until convergence with the total energy tolerance of $10^{-4} \mathrm{eV}$. The calculated lattice constants for bulk Mo and $\mathrm{Sb}$ were $3.16 \AA$ and $4.37 \AA / 11.59 \AA$ respectively, which agrees well with the experiments $(3.15 \AA$ and $4.31 \AA / 11.27 \AA$ ). ${ }^{[38,39]}$ For the doped system, one Mo (or Sb) atom was substituted by the Se atom in the 54-atom supercells, and other parameters used are the same as for the pure bulk system. The Se atom was modeled in a $(15 \AA \times 15.1 \AA \times 15.2 \AA)$ unit cell, using only the Gamma point in $\mathrm{k}$-space.

\section{Results and Discussions}

A schematic diagram of the whole process of the $\mathrm{Sb}_{2} \mathrm{Se}_{3}$ thin film solar cell fabrication is illustrated in Figure 1. Herein, the important combination reaction involved with sputtered and selenized $\mathrm{Sb}$ precursors have been investigated thoroughly. Homogeneous $\mathrm{Sb}$ metallic precursors were deposited onto Mo-coated glasses after careful optimization of the sputtering process. Subsequently, the sputtered precursors and $0.25 \mathrm{~g}$ of selenium $(\mathrm{Se})$ powder with high purity ( $>99.99 \%)$ were separately placed into the two chambers of a vacuum tubular furnace for selenization. The chambers were evacuated using a mechanical pump before introducing high-purity Ar gas. During the annealing process, the working pressure and the Se powder side temperature were kept at $5 \times 10^{4} \mathrm{~Pa}$ and $400{ }^{\circ} \mathrm{C}$, respectively whilst the $\mathrm{Sb}$ precursor side temperature and the selenization duration were carefully adjusted to obtain the $\mathrm{Sb}_{2} \mathrm{Se}_{3}$ thin films 
with desired orientation and crystallinity. Both the Se powder side temperature and the Sb precursor side temperature were ramped up to the set values at a heating rate of $20^{\circ} \mathrm{C} / \mathrm{min}$. The furanace was naturally cooled down to room temperature once the selenization was finished. Substrate temperature has been proven as a crucial factor for perfecting morphology of $\mathrm{Sb}_{2} \mathrm{Se}_{3}$ thin films in our previous report. ${ }^{[27]}$ Therefore, the effect of substrate temperature on the $\mathrm{Sb}_{2} \mathrm{Se}_{3}$ thin film morphology and device performance was firstly investigated by varying the $\mathrm{Sb}$ metallic side temperature from $325{ }^{\circ} \mathrm{C}$ to $425{ }^{\circ} \mathrm{C}$. The surface morphologies and chemical compositions of the $\mathrm{Sb}_{2} \mathrm{Se}_{3}$ thin films annealed at different temperatures are presented in Figure $\mathrm{S} 1$ (Supporting Information). Apparently, the grain sizes of the $\mathrm{Sb}_{2} \mathrm{Se}_{3}$ thin films are increased, indicating an evolution of crystallization and growth with increasing selenization temperature. The films were poorly crystallized when annealed at temperatures below $400{ }^{\circ} \mathrm{C}$ as small $\mathrm{Sb}_{2} \mathrm{Se}_{3}$ grains could be found all over the sample surface. Afterwards, the higher temperature could provide sufficient mobility for the $\mathrm{Sb}_{2} \mathrm{Se}_{3}$ molecules to pack together and facilitate the formation of larger $\mathrm{Sb}_{2} \mathrm{Se}_{3}$ grains. As a result, $\mathrm{Sb}_{2} \mathrm{Se}_{3}$ grains as large as $2 \mu \mathrm{m}$ were formed when selenization process was carried out at $400{ }^{\circ} \mathrm{C}$ and $425{ }^{\circ} \mathrm{C}$. The chemical composition of the thin film annealed at $400{ }^{\circ} \mathrm{C}$ is very close to its stoichiometric ratio (0.67). However, it can also be found that $\mathrm{Sb}_{2} \mathrm{Se}_{3}$ thin film annealed at $425{ }^{\circ} \mathrm{C}$ is severely Se-poor with a $\mathrm{Sb} / \mathrm{Se}$ ratio as high as 0.73 . We attribute this to the excessive annealing temperature that accelerated the evaporation rate of Se. It is reported that weight loss would start to occur from about $423{ }^{\circ} \mathrm{C}$ for $\mathrm{Sb}_{2} \mathrm{Se}_{3}$ and both $\mathrm{Sb}_{2} \mathrm{Se}_{3}$ and $\mathrm{Se}$ demonstrate very high vapor pressures at temperatures above $400{ }^{\circ} \mathrm{C} .{ }^{[12]}$ Annealing the substrate at $425^{\circ} \mathrm{C}$ would increase the extraction rate of Se from $\mathrm{Sb}_{2} \mathrm{Se}_{3}$, leading to the formation of Se vacancy defects and thus deteriorating the device performance. The performances of $\mathrm{Sb}_{2} \mathrm{Se}_{3}$ devices fabricated at different selenization temperatures are summarized in Figure S2 (Supporting Information) and Table S1 (Supporting Information), among them, the one selenized at $400{ }^{\circ} \mathrm{C}$ presents the highest PCE of $2.6 \%$. 
After analyzing the temperature effect, a range of selenization durations were selected to further optimize the $\mathrm{Sb}_{2} \mathrm{Se}_{3}$ thin film quality. The $\mathrm{Sb}$ precursor side temperature was fixed at $400{ }^{\circ} \mathrm{C}$ for each selenization scenario whilst the annealing duration was varied from 5 min to $30 \mathrm{~min}$ at an interval of $5 \mathrm{~min}$. The $\mathrm{SEM}$ top-view images as well as the $\mathrm{Sb} / \mathrm{Se}$ ratios of the $\mathrm{Sb}_{2} \mathrm{Se}_{3}$ thin films annealed at various selenization temperatures are shown in Figure 2. Prominent $\mathrm{Sb}_{2} \mathrm{Se}_{3}$ grain size development can be observed for the range of selenization duration from $5 \mathrm{~min}$ to $15 \mathrm{~min}$, indicating the rapid growth of $\mathrm{Sb}_{2} \mathrm{Se}_{3}$ crystals at the beginning stage of selenization. Prolonged annealing treatment did not bring a notable effect on crystallization as the $\mathrm{Sb}_{2} \mathrm{Se}_{3}$ grain sizes are almost constant. Moreover, it should be noted that insufficient or over extended annealing time would deviate the thin films from stoichiometric composition, making the samples become Se-poor or Se-rich, respectively. An optimal Sb/Se ratio of 0.67 could be obtained under selenization duration of $15 \mathrm{~min}$.

XRD results of $\mathrm{Sb}_{2} \mathrm{Se}_{3}$ thin films fabricated by various selenization scenarios are given in Figure 3a and Figure 3b. All the samples present a [221] preferred orientation which has been proven to be beneficial for carrier transport. ${ }^{[7,15,16]}$ Herein, texture coefficient (TC), an indicator of preferred crystal orientation, is applied on the (221) diffraction peak to quantitatively investigate the orientation preference along this particular direction. The TC values were calculated based on the following equation ${ }^{[15]}$ :

$$
T C_{h k l}=\frac{I(h k l)}{I_{0(h k l)}} /\left(\frac{1}{N} \sum_{i=1}^{N} \frac{I\left(h_{i} k_{i} l_{i}\right)}{\left.I_{0\left(h_{i} k_{i} l_{i}\right)}\right)}\right.
$$

where $\mathrm{I}_{(h k l)}$ and $\mathrm{I}_{0(h k l)}$ are the diffraction peak intensities of $(h k l)$ planes in the measured and standard XRD pattern of $\mathrm{Sb}_{2} \mathrm{Se}_{3}$ (JCPDS 15-0861), respectively. Large TC value of a diffraction peak indicates preferred orientation along this particular direction. ${ }^{[15]}$ It shows that the evolutions of (221) diffraction peaks (Figure 3c) and PCE (Figure 3d) of the $\mathrm{Sb}_{2} \mathrm{Se}_{3}$ thin film solar cells follow the same trend where the optimized condition could be obtained once the selenization was conducted at $400{ }^{\circ} \mathrm{C}$ for $15 \mathrm{~min}\left(15 \mathrm{~min}-\mathrm{Sb}_{2} \mathrm{Se}_{3}\right)$. Consistent with efficient 
$\mathrm{Sb}_{2} \mathrm{Se}_{3}$ thin film devices manufactured via other deposition techniques, ${ }^{[16,19,23]}$ the PCE of our devices correlates strongly with the orientation and crystallinity of the $\mathrm{Sb}_{2} \mathrm{Se}_{3}$ absorber layer. The current density-voltage $(J-V)$ curves and detailed performance parameters of the $\mathrm{Sb}_{2} \mathrm{Se}_{3}$ devices with different selenization durations are summarized in Figure 4a and Table 1. A competitive PCE of $6.15 \%$ was achieved for the $15 \mathrm{~min}-\mathrm{Sb}_{2} \mathrm{Se}_{3}$ device with the key device parameters namely, short circuit current density $\left(J_{S C}\right)$, open circuit voltage $\left(V_{O C}\right)$ and fill factor (FF) being $22.75 \mathrm{~mA} / \mathrm{cm}^{2}, 455 \mathrm{mV}$ and $59.5 \%$, respectively. 100 devices for both the $15 \mathrm{~min}$ $\mathrm{Sb}_{2} \mathrm{Se}_{3}$ and $20 \mathrm{~min}-\mathrm{Sb}_{2} \mathrm{Se}_{3}$ categories were tested to study the reproducibility of the devices and the main parameter boxplots of the two categories are illustrated in Supplementary Fig. S3. From the data it is clear that insufficient and over extended annealing durations would both bring a detrimental effect on the device performance. The external quantum efficiency (EQE) of the devices are provided in Figure $4 \mathrm{~b}$. The EQE responses demonstrate a dramatic decrease below approximately $520 \mathrm{~nm}$ which could be due to parasitic absorption of the CdS buffer layer. The $15 \mathrm{~min}-\mathrm{Sb}_{2} \mathrm{Se}_{3}$ device presents a substantially improved EQE at the visible region (400-750 $\mathrm{nm}$ ) compared with the other devices, implying less recombination losses both at the $\mathrm{Sb}_{2} \mathrm{Se}_{3} / \mathrm{CdS}$ interface and in the bulk film. ${ }^{[39]}$ We attribute this to the proper selenization process that not only passivated bulk defects but improved the adhesion at the heterojunction interface. At the longer wavelength region $(800-1100 \mathrm{~nm})$, the photo response of the $15 \mathrm{~min}-\mathrm{Sb}_{2} \mathrm{Se}_{3}$ device is also far stronger than that of the other devices, indicating less back interface recombination that originated from the micro-voids and small grains at the $\mathrm{MoSe}_{2} / \mathrm{Sb}_{2} \mathrm{Se}_{3}$ interface in this particular device. ${ }^{[40]}$ The $J-V$ measurements were also carried out for the $15 \mathrm{~min}-\mathrm{Sb}_{2} \mathrm{Se}_{3}$ device using different scanning directions (Figure 4c) and obviously there is no hysteresis between the forward and backward scans as two $J-V$ curves are overlapped perfectly. The champion device was placed in the ambient air without any special treatment/encapsulation for over 60 days to investigate the device stability. PCE of the device was measured every 5 days and the result is given in Figure $4 \mathrm{~d}$. The $15 \mathrm{~min}-\mathrm{Sb}_{2} \mathrm{Se}_{3}$ sample presented an outstanding device stability since 
only a slight performance degradation could be seen with PCE decreased from $6.15 \%$ to 5.46 $\%$ after long-term exposure to ambient air without any intentional storage.

In order to investigate the mechanisms of the improved performance of the $15 \mathrm{~min}-\mathrm{Sb}_{2} \mathrm{Se}_{3}$ device, dark $J-V$ characteristics were carried out for both the $15 \mathrm{~min}-\mathrm{Sb}_{2} \mathrm{Se}_{3}$ and $20 \mathrm{~min}-\mathrm{Sb}_{2} \mathrm{Se}_{3}$ samples. Figure 5a shows the $J-V$ curves of the two devices under dark condition. Shunt conductance $(\mathrm{G})$, series resistance $(R)$, diode ideality factor $(A)$ and reverse saturation current density $\left(J_{o}\right)$ of the two devices were calculated according to the Site's method, ${ }^{[41]}$ as in equation (2):

$$
J=J_{o} \exp \left[\frac{q}{A k T}(V-R J)\right]+G V-J_{L}
$$

The shunt conductance $G$ were obtained as 2.1 and $5.2 \mathrm{mS} / \mathrm{cm}^{2}$ for the $15 \mathrm{~min}-\mathrm{Sb}_{2} \mathrm{Se}_{3}$ and $20 \mathrm{~min}-\mathrm{Sb}_{2} \mathrm{Se}_{3}$ device respectively by extracting the flat regions of the plots of $\mathrm{d} J / \mathrm{d} V$ against $V$ under reverse bias, as shown in Figure 5 b. The series resistance $(R)$ can be obtained by extrapolating the plots of $\mathrm{d} J / \mathrm{d} V$ against $\left(J+J_{S C}\right)^{-1}$ to the $Y$-axis while the diode ideality factor (A) can be calculated as the slope of AkT/q (Figure 5c). ${ }^{[42]}$ The series resistance and diode ideality factor were calculated to be $R=8.03 \Omega / \mathrm{cm}^{2}, A=1.86$ and $R=11.61 \Omega / \mathrm{cm}^{2}, A=2.30$ for the $15 \mathrm{~min}-\mathrm{Sb}_{2} \mathrm{Se}_{3}$ and $20 \mathrm{~min}-\mathrm{Sb}_{2} \mathrm{Se}_{3}$ device respectively. The reverse saturation current density $\left(J_{o}\right)$ can be acquired by plotting the $\ln \left(J+J_{S C^{-}} G V\right)$ against $V-R J$ (Figure $5 \mathrm{~d}$ ) and the resulted $J_{o}$ for the $15 \mathrm{~min}-\mathrm{Sb}_{2} \mathrm{Se}_{3}$ and $20 \mathrm{~min}-\mathrm{Sb}_{2} \mathrm{Se}_{3}$ device are $4.3 \times 10^{-3}$ and $4.5 \times 10^{-4} \mathrm{~mA} / \mathrm{cm}^{2}$, respectively. It can be concluded from the above results that a suitable selenization duration could greatly improve the $\mathrm{Sb}_{2} \mathrm{Se}_{3} / \mathrm{CdS}$ heterojunction quality of the device, as evidence by the much smaller values of $J_{o}$ and $A$ for the $15 \mathrm{~min}-\mathrm{Sb}_{2} \mathrm{Se}_{3}$ sample. Moreover, the proper annealing time would also minimize the series resistance and thus enhancing the FF for the device.

The schematic diagram of the reaction and formation of $\mathrm{Sb}_{2} \mathrm{Se}_{3}$ thin films via selenization of $\mathrm{Sb}$ metallic precursors is illustrated in Figure 6. Sb metallic precursors were homogeneously deposited onto the Mo substrate using magnetron sputtering. The surface morphology of the as- 
deposited precursor is nearly featureless with only ripple-like $\mathrm{Sb}$ grains can be spotted, suggesting amorphous nature for the precursor. Once the selenization started a large amount of $\mathrm{Se}$ atoms would diffuse and react with the $\mathrm{Sb}$ lattice to form $\mathrm{Sb}_{2} \mathrm{Se}_{3}$ molecules under high temperature condition. The reaction would take place gradually towards the Mo substrate where the $\mathrm{Sb}$ precursor thin film would be consumed and turned into $\mathrm{Sb}_{2} \mathrm{Se}_{3}$ from the surface to the bottom of the absorber layer. As a result, it can be predicted that selenization duration would play a key role in the $\mathrm{Sb}_{2} \mathrm{Se}_{3}$ layer preparation. A short period of annealing time would not only prevent further chemical combination of Se vapor and Sb lattice towards the Mo substrate, but leads to insufficient crystallization for the upper layer of the $\mathrm{Sb}_{2} \mathrm{Se}_{3}$ thin film. Grain size distributions of $\mathrm{Sb}_{2} \mathrm{Se}_{3}$ thin films at an early stage $(\mathrm{t}=5 \mathrm{~min})$ and later stage $(\mathrm{t}=15 \mathrm{~min})$ of selenization are given in Figure S4 (Supporting Information). Obviously, the average grain size of the $\mathrm{Sb}_{2} \mathrm{Se}_{3}$ thin film was significantly enhanced once a proper annealing time had been applied, which could effectively hinder recombination losses originated from the grain boundaries.

On the other hand, excessively prolonged annealing time would be harmful to the device performance as well. Figure 7 shows the SEM cross-sectional morphology of Sb metallic precursor selenized at $400{ }^{\circ} \mathrm{C}$ for various annealing durations. It is seen that when the precursors were annealed for a relatively short period of time $(t=5 \mathrm{~min}$ and $\mathrm{t}=10 \mathrm{~min})$, small grains and voids appear at the bottom of the absorber layer owing to shallow Se diffusion. The sample annealed for $15 \mathrm{~min}$ (Figure 7c) is composed of large grains whose sizes are equivalent to the thickness of the absorber layer. Combined with the previous XRD results (Figure 3), it is suggested that self-assembled growth of $\mathrm{Sb}_{2} \mathrm{Se}_{3}$ thin films with significantly improved crystallinity and desired orientation have been achieved via sufficient combination reaction between the $\mathrm{Sb}$ metallic precursor and Se vapor under high temperature. In addition, the sample also shows good adhesion between the absorber layer and the back contact as no visible voids are present at the $\mathrm{Mo} / \mathrm{Sb}_{2} \mathrm{Se}_{3}$ interface. For the samples annealed over $15 \min (\mathrm{t}=20 \mathrm{~min}, \mathrm{t}=$ 
$25 \mathrm{~min}$ and $\mathrm{t}=30 \mathrm{~min}$ ), large voids can be clearly seen at the bottom of the $\mathrm{Sb}_{2} \mathrm{Se}_{3}$ layer, implying severe decomposition of the thin film materials due to over prolonged selenization durations. Such poor adhesion between the $\mathrm{Sb}_{2} \mathrm{Se}_{3}$ thin films and the Mo contact would significantly downgrade the carrier extraction ability and the device performance. In sum, highly crystalline stoichiometric $\mathrm{Sb}_{2} \mathrm{Se}_{3}$ thin films with [221] preferred orientation was fabricated through self-assembly via an effective combination reaction approach. Large $\mathrm{Sb}_{2} \mathrm{Se}_{3}$ grains with excellent continuity across the whole absorber layer as well as improved adhesion between the $\mathrm{Sb}_{2} \mathrm{Se}_{3}$ thin films and the Mo contact were achieved after careful optimization of the selenization process.

$\mathrm{MoSe}_{2}$ or $\mathrm{MoS}_{2}$ thin film layer is a common issue that has been extensively studied in many chalcogenide thin film solar cells such as CIGS, CZTSe, CZTSSe and $\mathrm{Sb}_{2} \mathrm{Se}_{3}$ in substrate configuration. ${ }^{[40,43-45]}$ It has been reported that such an interfacial layer between the absorber layer and Mo substrate with appropriate thickness could decrease the back contact barrier to improve the carrier transport and reduce the recombination loss. However, an over-thick interlayer will dramatically increase the series resistance of the device, leading to deterioration in PCE. Given that the over-thick interlayer would be prone to form within those thin film devices that are fabricated via high temperature selenization or sulfurization, it is vital to optimize the annealing process to control the thickness of the interfacial layer within a desired range. Herein, cross-sectional morphology of the champion device was characterized by TEM (Figure 8a) to investigate the formation of the $\mathrm{MoSe}_{2}$ interfacial layer. A thin interfacial layer with thickness less than $50 \mathrm{~nm}$ can be clearly observed between the Mo substrate and the $\mathrm{Sb}_{2} \mathrm{Se}_{3}$ layer. High-resolution transmission electron microscopy (HRTEM) imaging was performed at the $\mathrm{Sb}_{2} \mathrm{Se}_{3} / \mathrm{CdS}$ junction (Figure $8 \mathrm{~b}$ ) and it is obvious the heterojunction is of high quality as smooth interface is present between the $\mathrm{Sb}_{2} \mathrm{Se}_{3}$ layer and $\mathrm{CdS}$ buffer layer without abrupt interfacial boundary. Further, lattice fringe distances of three arbitrary points $a, b$ and $c$ that were randomly selected near the top, middle and bottom regions of the $\mathrm{Sb}_{2} \mathrm{Se}_{3}$ thin film were 
measured, as shown in Figure 8c-e. As can be seen from the results the distances between the lattice lines, namely $0.284 \mathrm{~nm}$ and $0.315 \mathrm{~nm}$, which correspond to the (221) and (211) planes in $\mathrm{Sb}_{2} \mathrm{Se}_{3}$, are highly consistent for the three measuring points. Such a vertical preferred crystal orientation across the whole $\mathrm{Sb}_{2} \mathrm{Se}_{3}$ film would facilitate facile charge carrier transport within the light absorber layer and thus improving the device performance. ${ }^{[7]}$ Energy dispersive spectroscopy (EDS) elemental profiles were then conducted for the $15 \mathrm{~min}-\mathrm{Sb}_{2} \mathrm{Se}_{3}$ and $20 \mathrm{~min}-$ $\mathrm{Sb}_{2} \mathrm{Se}_{3}$ sample to compare the $\mathrm{MoSe}_{2}$ thickness of the two devices quantitatively (Figure 8f). For both devices, elemental profile crossover of Mo and Se could be found, implying the existence of $\mathrm{MoSe}_{2}$ interfacial layer in the two devices. It should also be noted that the crossover region become broad as severe Mo and Se tails are apparent for the 20 min- $\mathrm{Sb}_{2} \mathrm{Se}_{3}$ devices, suggesting the thickness increase of the $\mathrm{MoSe}_{2}$ layer due to prolonged annealing time. The over-thick $\mathrm{MoSe}_{2}$ interfacial layer is believed to be responsible for the poor FF of the 20 min$\mathrm{Sb}_{2} \mathrm{Se}_{3}$ device (49.8\%). In addition, high-angle annular dark-field scanning transmission electron microscope (HAADF-STEM) equipped with EDS was performed for the champion device and no overlap phenomenon could be observed between the elemental mapping results of Mo and Se (Figure 8g), hinting that no or a very thin interfacial layer might exist between the Mo substrate and the absorber layer. To further explore the effect of the $\mathrm{MoSe}_{2}$ interfacial layer in magnetron sputtered $\mathrm{Sb}_{2} \mathrm{Se}_{3}$ thin film solar cells, it is important to be reminded that the device of our previous work contained a relatively thick $\operatorname{MoSe}_{2}$ layer $(\sim 200 \mathrm{~nm}){ }^{[27]}$, on the other hand a much thinner $\mathrm{MoSe}_{2}$ thin film with thickness less than $50 \mathrm{~nm}$ is present in the device of this work. This prominent difference in $\mathrm{MoSe}_{2}$ thickness can be attributed to fabrication variation of the two methods. In this project, crystallized $\mathrm{Sb}_{2} \mathrm{Se}_{3}$ thin film was prepared by selenization of $\mathrm{Sb}$ metallic precursors under high temperature. During the selenization process Se vapor would diffuse into the metallic precursor lattice and react with the $\mathrm{Sb}$ atoms. The combination reaction took place from the sample surface towards the bottom of the film, turning the $\mathrm{Sb}$ precursor into $\mathrm{Sb}_{2} \mathrm{Se}_{3}$ compound gradually. At the early stage of 
selenization, the upper layer of the $\mathrm{Sb}$ precursor would be fully consumed and became $\mathrm{Sb}_{2} \mathrm{Se}_{3}$ compound, while leaving the lower layer unaffected. DFT calculations were conducted using VASP5.3, ${ }^{[31,32]}$ with the all-electron projector augmented wave (PAW) method ${ }^{[33,34]}$ in this work. When one Mo or Se atom was substituted by one Se atom in the periodic supercells, the energy change $\Delta E$ was calculated as $\Delta E=E_{\mathrm{total}}+E_{\mathrm{Mo}(\mathrm{or} \mathrm{Sb})}-E_{\mathrm{bulk}}-E_{\mathrm{Se}}$, which is the energy gain with respect to the Se atom in the gas phase and the metal atoms in the bulk phase. $E_{\text {total }}$ and $E_{\text {bulk }}$ are the total energy of the doped system and the pure metal system in the periodic supercells, respectively. $E_{\mathrm{Mo}(\mathrm{or} \mathrm{Sb})}$ and $E_{\mathrm{Se}}$ are the calculated energy of one Mo (or $\mathrm{Sb}$ ) atom in the bulk phase and one Se atom in the gas phase, respectively. Here a negative (positive) value indicates that the substitution is exothermic (endothermic). Our DFT calculations show that when $1 / 54 \mathrm{Sb}$ atoms were substituted by $\mathrm{Se}$ atoms in the bulk $\mathrm{Sb}$, the energy change is -2.54 $\mathrm{eV}$, which is $1.31 \mathrm{eV}$ lower than the corresponding process in the bulk Mo system (as shown in Figure S5, Supporting Information), suggesting the reaction between Se and Sb is energetically favorable than that between Se and Mo. As a result, Se vapor would preferentially react with the $\mathrm{Sb}$ precursor during the annealing process, and meanwhile, hinder the reaction with Mo substrate thus limiting the $\mathrm{MoSe}_{2}$ thickness. Therefore, it is logical to presume the thickness of the $\mathrm{MoSe}_{2}$ interfacial layer can be well controlled once a proper annealing duration is applied. However, the situation was quite different in our last work where amorphous $\mathrm{Sb}_{2} \mathrm{Se}_{3}$ thin films were used as precursors for post-selenization. Excessive Se vapor would penetrate through the $\mathrm{Sb}_{2} \mathrm{Se}_{3}$ thin film with ease, without being consumed and react with the Mo substrate. Moreover, the bottom part of the amorphous $\mathrm{Sb}_{2} \mathrm{Se}_{3}$ thin film that adjacent to the Mo substrate would be prone to evaporate under high temperature and produce even more Se vapor which could further facilitate the formation of $\mathrm{MoSe}_{2}$ interlayer. As a consequence, an over-thick $\mathrm{MoSe}_{2}$ interfacial layer is usually present in devices fabricated by post-selenization of $\mathrm{Sb}_{2} \mathrm{Se}_{3}$ amorphous thin films, introducing severe recombination at the $\mathrm{Sb}_{2} \mathrm{Se}_{3} / \mathrm{MoSe}_{2}$ interface and significant $\mathrm{FF}$ deterioration of the device. 
Efficiency records of planar heterojunction $\mathrm{Sb}_{2} \mathrm{Se}_{3}$ thin film solar cells in substrate configuration fabricated by various techniques are summarized in Table 2 . It can be seen that our champion device with a highly interesting PCE of $6.15 \%$ is comparable to the state-of-theart devices and represents the highest efficiency of sputtered $\mathrm{Sb}_{2} \mathrm{Se}_{3}$ solar cells. Additionally, the competitive FF (59.5\%) of our champion device is really attributed to the ultrathin $\mathrm{MoSe}_{2}$ interlayer, whose growth could be naturally hindered during the combination reaction of the sputtered and selenized Sb metallic precursors.

Capacitance-voltage $(C-V)$ profiling and deep-level capacitance profiling $(D L C P)$ characterizations were carried out to investigate interfacial properties of the devices (Figure 9a). In general, the $C$ - $V$ measured doping density $\left(N_{C-V}\right)$ includes free carriers, bulk defects and interfacial defects, whilst the $D L C P$ measured doping density $\left(N_{D L C P}\right)$ only represents responses from free carriers and bulk defects. ${ }^{[46]}$ Therefore, the interfacial defect density of the device can be calculated as the subtraction of $N_{D L C P}$ from $N_{C-V}$. The plots of $N_{C-V}$ and $N_{D L C P}$ against the profiling depth $x$ can be expressed as the following equations,

$$
\left\{\begin{array}{l}
N_{C-V}=\frac{-2 \varepsilon_{r, n} N_{D}}{\left(\frac{d\left(1 / C^{2}\right)}{d V}\right) q A^{2} \varepsilon_{0} \varepsilon_{r, n} \varepsilon_{r, p} N_{D}+2 \varepsilon_{r, p}} \\
N_{D L C P}=-\frac{C_{0}^{3}}{2 q \varepsilon_{0} \varepsilon_{r, p} A^{2} C_{1}} \\
x=\varepsilon_{0} \varepsilon_{r, p} A / C_{0}
\end{array}\right.
$$

where $\varepsilon_{r, n}$ and $\varepsilon_{r, p}$ are the relative permittivity of $\mathrm{CdS}$ and $\mathrm{Sb}_{2} \mathrm{Se}_{3}$, respectively, $N_{D}$ is the doping density of $\mathrm{CdS}, A$ is the device area, $C_{0}$ and $C_{1}$ are two quadratic fitting parameters derived from the $C-V$ curves. For the $20 \mathrm{~min}-\mathrm{Sb}_{2} \mathrm{Se}_{3}$ device, a gap can be clearly observed between the $N_{C-V}$ and $N_{D L C P}$ curves. However, the difference between the two curves is much smaller in the $15 \mathrm{~min}-\mathrm{Sb}_{2} \mathrm{Se}_{3}$ device, indicating lower defect density and less severe recombination at the $\mathrm{Sb}_{2} \mathrm{Se}_{3} / \mathrm{CdS}$ heterojunction for the device. This could be attributed to the properly optimized selenization duration which could effectively passivate the interfacial defects originated from 
dangling-bond-rich grain boundaries by producing more favorable orientation and crystallinity for the $\mathrm{Sb}_{2} \mathrm{Se}_{3}$ thin film. In addition, it should be noted that from Figure 9, the $15 \mathrm{~min}-\mathrm{Sb}_{2} \mathrm{Se}_{3}$ device possesses a wider depletion region, which might enhance light absorption and carrier extraction ability of the device.

To further investigate the dominant recombination type of our devices, temperaturedependent open circuit voltage $\left(V_{O C}-T\right)$ measurements were undertaken from $400 \mathrm{~K}$ to $100 \mathrm{~K}$ and activation energy $E_{a}$ of recombination processes of the devices can be calculated by extrapolating the $V_{O C}$ to the $\mathrm{Y}$-axis, as shown in Figure $9 \mathrm{~b}$. Both the devices possess an $E_{a}$ a bit lower than the optical bandgap of the $\mathrm{Sb}_{2} \mathrm{Se}_{3}$ absorber (1.2eV, as estimated from the EQE data), implying the device performance losses were dominated by the Schottky-Read-Hall recombination in the depletion regions. ${ }^{[40]}$ The lower $E_{a}$ suggests that there exists more serious interfacial recombination for the $20 \mathrm{~min}-\mathrm{Sb}_{2} \mathrm{Se}_{3}$ device which might be originated from the over-thick $\mathrm{MoSe}_{2}$ interfacial layer as well as poor adhesion between the $\mathrm{Sb}_{2} \mathrm{Se}_{3}$ absorber and Mo substrate due to the large voids at the $\mathrm{Mo} / \mathrm{Sb}_{2} \mathrm{Se}_{3}$ interface (Figure 7d). Electron beaminduced current (EBIC) measurements were conducted to explore the carrier collection efficiency of the devices (Figure 9c). As expected, light areas that indicating high collection efficiency regions locate at the $\mathrm{Sb}_{2} \mathrm{Se}_{3} / \mathrm{CdS}$ interfaces for the both devices. Apparently, the light area of the $15 \mathrm{~min}-\mathrm{Sb}_{2} \mathrm{Se}_{3}$ device is wider than that of the 20 min- $\mathrm{Sb}_{2} \mathrm{Se}_{3}$ device, suggesting a longer depletion region for the $15 \mathrm{~min}-\mathrm{Sb}_{2} \mathrm{Se}_{3}$ device, which is consistent with the $C$ - $V$ measurement results. Furthermore, compared to the $15 \mathrm{~min}-\mathrm{Sb}_{2} \mathrm{Se}_{3}$ device, the $20 \mathrm{~min}-\mathrm{Sb}_{2} \mathrm{Se}_{3}$ device presents a light area with lower brightness, indicating significant carrier recombination possibly due to excessive interfacial defects, which echoes the observations of the $C-V$ and $D L C P$ measurements. EBIC signals were scanned across the device for both the samples (Figure 9d), the signals were normalized to the maximum value and the decay rate of the $15 \mathrm{~min}$ $\mathrm{Sb}_{2} \mathrm{Se}_{3}$ device is slower than that of the $20 \mathrm{~min}-\mathrm{Sb}_{2} \mathrm{Se}_{3}$ device over the whole device, implying 
a substantial enhancement of the carrier collection efficiency at both the front electrode and deep absorber. ${ }^{[18]}$

Admittance spectroscopy has been regarded as a useful tool to investigate defect properties in conventional thin film solar cell characterizations. ${ }^{[17,47,48]}$ In order to get a deeper understand of distribution and density of defects as well as defect-induced carrier recombination mechanisms for our devices, temperature-dependent admittance $(C-f-T)$ measurements were conducted in the temperature range of 180 to $330 \mathrm{~K}$ and the $C-f-T$ spectra of our champion device $\left(6.15 \%, 15\right.$ min- $\left.\mathrm{Sb}_{2} \mathrm{Se}_{3}\right)$ are demonstrated in Figure 10. Three peaks were distinguished from the $\omega d C / d \omega$ plots (not shown here) that could be ascribed to three defect levels, denoted as D1, D2 and D3 within our devices, which is consistent with defect characterizations of $\mathrm{Sb}_{2} \mathrm{Se}_{3}$ solar cells in literature. ${ }^{[18]}$ Angular frequency point $\omega$ at the maximum of the $\omega d C / d \omega$ plot was defined as the inflection point frequency $\omega_{0}$ for each $C-f-T$ curve. The defect activation energies $\left(E_{a}\right)$ were derived from the slopes of the Arrhenius plots that were linearly fitted based on the equation:

$$
\omega_{0}=2 \pi v_{0} T^{2} \exp \left(\frac{-E_{a}}{k T}\right)
$$

where $v_{0}$ is the attempt-to-escape frequency, $\omega_{0}$ is the inflection point frequency and $E_{a}$ is the defect activation energy that represents the average energetic depth of the defect relative to the valence band maximum (VBM) or conduction band minimum $(\mathrm{CBM}) \cdot{ }^{[48]}$ The distribution of each defect type was Gaussian fitted using the Kimerling model based on the following equation:

$$
\begin{gathered}
E(\omega)=k T \ln \left(\frac{2 \pi v_{0} T^{2}}{\omega}\right) \\
N_{t}(E(\omega))=-\frac{V_{d}}{q \omega} \cdot \frac{d C}{d \omega} \cdot \frac{\omega}{k T}
\end{gathered}
$$


where $V_{d}$ is the built-in potential of the p-n junction, $\omega$ is the angular frequency and $N_{t}(E(\omega))$ is the defect density. The detailed defect parameters of the $15 \mathrm{~min}-\mathrm{Sb}_{2} \mathrm{Se}_{3}$ and $20 \mathrm{~min}-\mathrm{Sb}_{2} \mathrm{Se}_{3}$ devices are summarized in Table 3. Since our $\mathrm{Sb}_{2} \mathrm{Se}_{3}$ thin films were subjected to overabundant Se vapor during the selenization process due to the high vapor pressure of Se under elevated temperature, the $\mathrm{Sb}_{2} \mathrm{Se}_{3}$ films were slightly Se rich. DFT calculations have revealed that three types of intrinsic defects, namely, $\mathrm{Sb}$ vacancy $\mathrm{V}_{\mathrm{Sb}}, \mathrm{Se}_{\mathrm{Sb}}$ antisite and $\mathrm{Se}$ interstitial $\mathrm{Se} \mathrm{i}_{\mathrm{i}}$, are dominating within $\mathrm{Sb}_{2} \mathrm{Se}_{3}$ devices that were fabricated under Se-rich growth conditions. ${ }^{[49,50]}$ A small gap of activation energy is observed between the two devices for each defect level and thus it is legal to claim that the defect types are identical for the two devices. It is almost certain that D1 with lowest activation energy could be assigned to $\mathrm{V}_{\mathrm{Sb}}$ defects, which are shallow acceptors that could be easily formed under Se-rich environments. D2, D3 with higher activation energies can be assigned to $\mathrm{Se}_{\mathrm{i}}$ and $\mathrm{Se}_{\mathrm{Sb}}$ defects respectively, according to the DFT simulation results. ${ }^{[49]}$ Although $\mathrm{Se}_{\mathrm{i}}$ has a deep energy level, the defect ionization level is higher than the CBM. Hence it is unlikely for these defects act as recombination centers and their impacts on the performance losses of the devices are thus minimized. Since $\mathrm{V}_{\mathrm{Sb}}$ are shallow acceptors with very low activation energy and given that the defect density is relatively low, the contribution of this defect state to the recombination losses will be limited as well. On the other hand, $\mathrm{Se}_{\mathrm{Sb}}$ antisite has been reported as one of the dominant defect states for $\mathrm{Sb}_{2} \mathrm{Se}_{3}$ solar cells. ${ }^{[16]}$ Due to the high activation energy, the energy level of $\mathrm{Se}_{\mathrm{Sb}}$ defects is quite close to the midgap, turning the defects into effective trapping centers that greatly increase the recombination probability of charge carriers. From Table 3, it is seen that the defect densities of D1 and D2, i.e. $\mathrm{V}_{\mathrm{Sb}}$ and $\mathrm{Se}_{\mathrm{i}}$, are almost identical for both devices. However, the defect density of D3, i.e. $\mathrm{Se}_{\mathrm{Sb}}$ of the $20 \mathrm{~min}-\mathrm{Sb}_{2} \mathrm{Se}_{3}$ device is one order of magnitude larger than that of the $15 \mathrm{~min}-\mathrm{Sb}_{2} \mathrm{Se}_{3}$ device. We attribute the massive antisite defects to over extended annealing duration for the 20 min- $\mathrm{Sb}_{2} \mathrm{Se}_{3}$ devices. Based on DFT calculations, when subjected to high temperature, $\mathrm{Se}$ atoms are prone to substitute $\mathrm{Sb}$ atoms thermodynamically under Se rich 
environment. Such a large amount of antisite defects with deep energy level will act as recombination centers and significantly affect photovoltaic performance of the device.

\section{Conclusion}

In summary, $\mathrm{Sb}_{2} \mathrm{Se}_{3}$ thin film solar cells were fabricated by an effective combination reaction of sputtered Sb metallic precursors. A champion device with a highly interesting PCE of $6.15 \%$ that represents the highest efficiency of sputtered $\mathrm{Sb}_{2} \mathrm{Se}_{3}$ solar cells has been successfully obtained. Self-assembled growth of $\mathrm{Sb}_{2} \mathrm{Se}_{3}$ thin films consist of large grains with excellent continuity across the whole films was achieved via this combination reaction. Highlycrystallized $\mathrm{Sb}_{2} \mathrm{Se}_{3}$ with the desired [221] preferred orientation, stoichiometric composition as well as an optimized $\mathrm{Sb}_{2} \mathrm{Se}_{3} / \mathrm{CdS}$ heterojunction were obtained under a proper selenization scenario. Moreover, by utilizing the $\mathrm{Sb}$ metallic precursors for post-selenization heat treatment, the thickness of the interfacial $\mathrm{MoSe}_{2}$ layer between the Mo substrate and $\mathrm{Sb}_{2} \mathrm{Se}_{3}$ light absorber layer could be efficiently tailored. Our DFT simulation results further confirmed that Se vapor would be prone to react with the $\mathrm{Sb}$ lattice energetically, therefore an over-thick disadvantageous $\mathrm{MoSe}_{2}$ layer that prevalently existed in Mo substrate coupled $\mathrm{Sb}_{2} \mathrm{Se}_{3}$ solar cells could be effectively prevented. As a result, the corresponding FF of our champion device has dramatically increased from a poor value of $47 \%$ (in our previous work) to $59.5 \%$ (in this work). In addition, a systematic investigation of interfacial properties and defect properties demonstrated that a suitable annealing duration is really beneficial for reducing deep defect density within the device. Nevertheless, $J_{S C}$ was found to be the major obstacle for our device when compared with those first-tier $\mathrm{Sb}_{2} \mathrm{Se}_{3}$ thin film solar cells where non-toxic or additional buffer layers were used. Comprehensive understanding of interface engineering would be urgently required to further improve the device efficiency in future work.

\section{Acknowledgements}

This work was supported by Key Project of Department of Education of Guangdong Province (No. 2018KZDXM059), Science and Technology plan project of Shenzhen (20190726221232961), National Natural Science Foundation of China (No. 61404086, 
51802050, U1804160, 21603146), The Natural Science Foundation of Guizhou Province (Qian $\mathrm{Ke} \mathrm{He}$ [2017]1064), The postgraduate innovation development fund project of Shenzhen University (PIDFP-ZR2019019), Shenzhen Key Lab Fund (ZDSYS 20170228105421966), Science and Technology plan project of Shenzhen (JCYJ20180305124340951). The authors wish to acknowledge the assistance on HAADF-STEM observation received from the Electron Microscope Center of the Shenzhen University.

\section{References}

[1] Green, M. A. et al. Solar cell efficiency tables (version 51) Prog. Photovolt. Res. Appl. 26 (2018) 3-12.

[2] Solar Frontier. Solar Frontier achieves world record thin-film solar cell efficiency of 22.9\%.

Solar. Frontier. http://www.solar-frontier.com/eng/news/2017/1220 press.html (2017) Accessed June 2018.

[3] Yang W S, Noh J H, Jeon N J, et al. High-performance photovoltaic perovskite layers fabricated through intramolecular exchange. Science 348(6240) (2015) 1234-1237.

[4] Chen, C. et al. Characterization of basic physical properties of $\mathrm{Sb}_{2} \mathrm{Se}_{3}$ and its relevance for photovoltaics. Front. Optoelectron. 10 (2017) 18-30.

[5] Yuan, C, et al. Rapid thermal process to fabricate $\mathrm{Sb}_{2} \mathrm{Se}_{3}$ thin film for solar cell application. Sol. Energy 137 (2016) 256-260.

[6] Shen, K. et al. Mechanisms and modification of nonlinear shunt leakage in $\mathrm{Sb}_{2} \mathrm{Se}_{3}$ thin film solar cells, Sol. Energy Mater. Sol. Cells 186 (2018) 58-65.

[7] Zhou, Y. et al. Thin-film $\mathrm{Sb}_{2} \mathrm{Se}_{3}$ photovoltaics with oriented one-dimensional ribbons and benign grain boundaries. Nat. Photon. 9 (2015) 409-415.

[8] Zhou, Y. et al. Solution-processed antimony selenide heterojunction solar cells. Adv. Energy Mater. 4 (2014) 1079-1083.

[9] Guo H. F, et al. Significant increase in efficiency and limited toxicity of a solar cell based on $\mathrm{Sb}_{2} \mathrm{Se}_{3}$ with $\mathrm{SnO}_{2}$ as a buffer layer. J. Mater. Chem. C 7(45) (2019) 14350-14356.

[10] Wang, W. et al. Over 6\% Certified $\mathrm{Sb}_{2}(\mathrm{~S}, \mathrm{Se})_{3}$ solar cells fabricated via in situ hydrothermal growth and post-selenization, Adv. Electron Mater. 5 (2018) 1800683.

[11] Cheng, J, et al. Air Stable Solar Cells with 0.7 V Open Circuit Voltage Using Selenized Antimony Sulfide Absorbers Prepared by Hydrazine Free Solution Method. Sol. RRL 3(5) (2019) 1800346.

[12] Liu, X. et al. Thermal evaporation and characterization of $\mathrm{Sb}_{2} \mathrm{Se}_{3}$ thin film for substrate $\mathrm{Sb}_{2} \mathrm{Se}_{3} / \mathrm{CdS}$ solar cells. ACS Appl. Mater. Interfaces 6 (2014) 10687-10695. 
[13] Leng, M. et al. Selenization of $\mathrm{Sb}_{2} \mathrm{Se}_{3}$ absorber layer: an efficient step to improve device performance of CdS/ $\mathrm{Sb}_{2} \mathrm{Se}_{3}$ solar cells. Appl. Phys. Lett. 105 (2014) 083905.

[14] Liu, X. et al. Improving the performance of $\mathrm{Sb}_{2} \mathrm{Se}_{3}$ thin film solar cells over 4\% by controlled addition of oxygen during film deposition. Prog. Photo. Res. Appl. 23 (2015) 18281836.

[15] Wang, L. et al. Stable 6\%-efficient $\mathrm{Sb}_{2} \mathrm{Se}_{3}$ solar cells with a $\mathrm{ZnO}$ buffer layer. Nat. Energy 2 (2017) 17046.

[16] Wen, X. et al. Vapor transport deposition of antimony selenide thin film solar cells with 7.6\% efficiency. Nat. Commun. 9 (2018) 2179.

[17] $\mathrm{Hu}, \mathrm{X}$. B. et al. Improving the efficiency of $\mathrm{Sb}_{2} \mathrm{Se}_{3}$ thin-film solar cells by post annealing treatment in vacuum condition. Sol. Energy Mater. Sol. Cells 187 (2018) 170-175.

[18] Tao, J. et al. Solution-processed $\mathrm{SnO}_{2}$ interfacial layer for highly efficient $\mathrm{Sb}_{2} \mathrm{Se}_{3}$ thin film solar cells. Nano Energy 60 (2019) 802-809.

[19] Li, Z. Q. et al. 9.2\%-efficient core-shell structured antimony selenide nanorod array solar cells. Nat. Commun. 10 (2019) 125.

[20] $\mathrm{Li}$, D. et al Stable and efficient $\mathrm{CdS} / \mathrm{Sb}_{2} \mathrm{Se}_{3}$ solar cells prepared by scalable close space sublimation. Nano Energy 49 (2018) 346-353.

[21] Liang, G. X. et al. Facile preparation and enhanced photoelectrical performance of $\mathrm{Sb}_{2} \mathrm{Se}_{3}$ nano-rods by magnetron sputtering deposition. Sol. Energy Mater. Sol. Cells 160 (2017) 257262.

[22] Liang, G. X. et al. Thermally induced structural evolution and performance of $\mathrm{Sb}_{2} \mathrm{Se}_{3}$ films and nanorods prepared by an easy sputtering method. Sol. Energy Mater. Sol. Cells 174 (2018) $263-270$.

[23] $\mathrm{Li}, \mathrm{G}$ et al. Improvement in $\mathrm{Sb}_{2} \mathrm{Se}_{3}$ Solar Cell Efficiency through Band Alignment Engineering at the Buffer/Absorber Interface. Appl. Mater. Interfaces 11 (2019) 828-834.

[24] Shi, J. H. et al. Fabrication of $\mathrm{Cu}(\mathrm{In}, \mathrm{Ga}) \mathrm{Se}_{2}$ thin films by sputtering from a single quaternary chalcogenide target. Prog. Photovolt. Res. Appl. 19(2) (2011) 160-164.

[25] Yan, C. et al. $\mathrm{Cu}_{2} \mathrm{ZnSnS}_{4}$ solar cells with over $10 \%$ power conversion efficiency enabled by heterojunction heat treatment. Nat Energy 3(9) (2018) 764.

[26] Chawla et al. Effect of composition on high efficiency CZTSSe devices fabricated using co-sputtering of compound targets. In 2012 38th IEEE Photovoltaic Specialists Conference (2012) 002990-002992. IEEE.

[27] Tang, R, et al. Highly efficient and stable planar heterojunction solar cell based on sputtered and post-selenized $\mathrm{Sb}_{2} \mathrm{Se}_{3}$ thin film. Nano Energy 64 (2019) 103929. 
[28] Ganchev, M, et al. Preparation of $\mathrm{Cu}(\mathrm{In}, \mathrm{Ga}) \mathrm{Se}_{2}$ layers by selenization of electrodeposited $\mathrm{Cu}-\mathrm{In}-\mathrm{Ga}$ precursors. Thin Solid Films 511 (2006) 325-327.

[29] Yao, L, et al. CZTSe solar cells prepared by electrodeposition of $\mathrm{Cu} / \mathrm{Sn} / \mathrm{Zn}$ stack layer followed by selenization at low Se pressure. Nanoscale Res Lett. 9(1) (2014) 678.

[30] Salomé, P. M. P., et al. Growth and characterization of $\mathrm{Cu}_{2} \mathrm{ZnSn}(\mathrm{S}, \mathrm{Se})_{4}$ thin films for solar cells. Sol. Energy Mater. Sol. Cells 101 (2012) 147-153.

[31] Kresse, G. Furthmüller, J., Efficient Iterative Schemes for Ab Initio Total-Energy Calculations Using a Plane-Wave Basis Set. Phys. Rev. B 54 (1996) 11169-11186.

[32] Kresse, G. Furthmüller, J., Efficiency of Ab-Initio Total Energy Calculations for Metals and Semiconductors Using a Plane-Wave Basis Set. Comp. Mater. Sci. 6 (1996) 15-50.

[33] Blöchl, P. E., Projector Augmented-Wave Method. Phys. Rev. B 50 (1994) 17953-17979.

[34] Kresse, G. Joubert, D., From Ultrasoft Pseudopotentials to the Projector Augmented-Wave Method. Phys. Rev. B 59 (1999) 1758-1775.

[35] Perdew, J. P. Burke, K. Ernzerhof, M., Generalized Gradient Approximation Made Simple. Phys. Rev. Lett. 77 (1996) 3865-3868.

[36] Monkhorst, H. J. Pack, J. D., Special Points for Brillouin-Zone Integrations. Phys. Rev. B 13 (1976) 5188-5192.

[37] Ross, R. G. Hume-Rothery, W, High Temperature X-Ray Metallography: I. A New DebyeScherrer Camera for Use at Very High Temperatures Ii. A New Parafocusing Camera Iii. Applications to the Study of Chromium, Hafnium, Molybdenum, Rhodium, Ruthenium and Tungsten. J. Less Common Metals, 5 (1963) 258-270.

[38] Schiferl, D., 50-Kilobar Gasketed Diamond Anvil Cell for Single-Crystal X-Ray Diffractometer Use with the Crystal Structure of Sb up to 26 Kilobars as a Test Problem. Rev. Sci. Instrum. 48 (1977) 24-30.

[39] $\mathrm{Su}, \mathrm{Z} . \mathrm{H}$, et al. Fabrication of $\mathrm{Cu}_{2} \mathrm{ZnSnS}_{4}$ solar cells with $5.1 \%$ efficiency via thermal decomposition and reaction using a non-toxic sol-gel route. J. Mater. Chem. A 2(2) (2014) 500509.

[40] Li, J. J, et al. A temporary barrier effect of the alloy layer during selenization: tailoring the thickness of $\mathrm{MoSe}_{2}$ for efficient $\mathrm{Cu}_{2} \mathrm{ZnSnSe}_{4}$ solar cells. Adv. Energy Mater. 5(9) (2015) 1402178.

[41] Sites JR, et al. Diode quality factor determination for thin-film solar cells. Sol. Cells 27 (1989) 411-417.

[42] Ishaq, M., et al. Efficient Double Buffer Layer $\mathrm{Sb}_{2}\left(\mathrm{Se}_{\mathrm{x}} \mathrm{S}_{1-\mathrm{x}}\right)_{3}$ Thin Film Solar Cell Via Single Source Evaporation. Sol. RRL, 2(10) (2018) 1800144. 
[43] Chirila, A. et al. Highly efficient $\mathrm{Cu}(\mathrm{In}, \mathrm{Ga}) \mathrm{Se}_{2}$ solar cells grown on flexible polymer films. Nat. mater. 10 (2011) 857-861.

[44] Li, J. J, et al. $10 \%$ Efficiency $\mathrm{Cu}_{2} \mathrm{ZnSn}(\mathrm{S}, \mathrm{Se})_{4}$ thin film solar cells fabricated by magnetron sputtering with enlarged depletion region width. Sol. Energy Mater. Sol. Cells 149 (2016) 242249.

[45] Li, Z. Q, et al. $\mathrm{Sb}_{2} \mathrm{Se}_{3}$ thin film solar cells in substrate configuration and the back contact selenization. Sol. Energy Mater. Sol. Cells 161 (2017) 190-196.

[46] Liu, S. C, et al. GeSe thin-film solar cells. Mater. Chem. Front. (2020) https://doi.org/ $10.1039 / \mathrm{c} 9 \mathrm{qm} 00727 \mathrm{j}$

[47] $\mathrm{Hu}, \mathrm{X}$. B, et al. Investigation of electrically-active defects in $\mathrm{Sb}_{2} \mathrm{Se}_{3}$ thin-film solar cells with up to $5.91 \%$ efficiency via admittance spectroscopy. Sol. Energy Mater. Sol. Cells. 186 (2018) 324-329.

[48] Li, J. J, et al. Tailoring the defects and carrier density for beyond $10 \%$ efficient CZTSe thin film solar cells. Sol. Energy Mater. Sol. Cells. 159 (2017) 447-455.

[49] Liu, X. S. et al. Enhanced $\mathrm{Sb}_{2} \mathrm{Se}_{3}$ solar cell performance through theory-guided defect control. Prog. Photovolt. Res. Appl. 25 (10) (2017) 861-870.

[50] Guo, H. F. et al. Enhancement in the Efficiency of $\mathrm{Sb}_{2} \mathrm{Se}_{3}$ Thin Film Solar Cells by Increasing Carrier Concertation and Inducing Columnar Growth of the Grains. Sol. RRL 3 (3) (2019): 1800224.

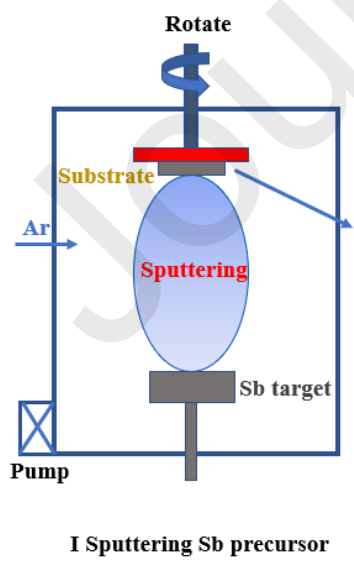

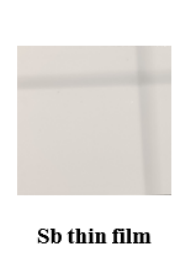

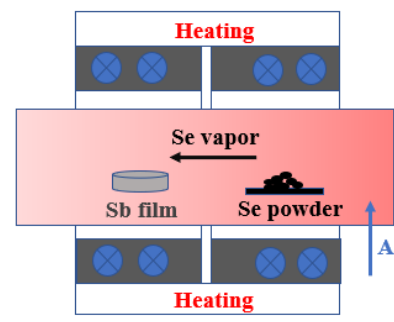

II Post-selenization

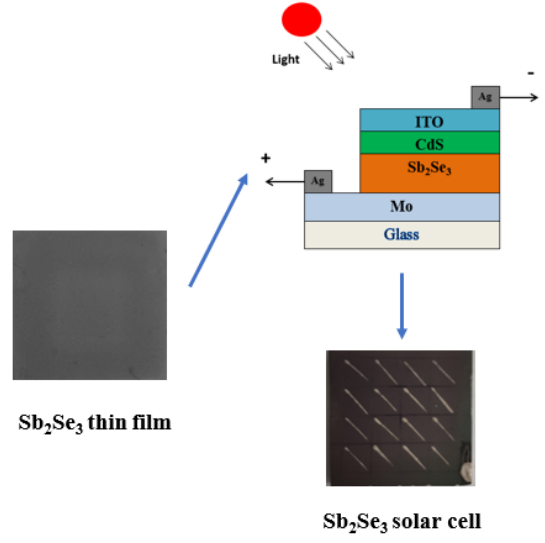

III Device fabrication

Figure 1. Schematic diagram of the $\mathrm{Sb}_{2} \mathrm{Se}_{3}$ device fabrication. 

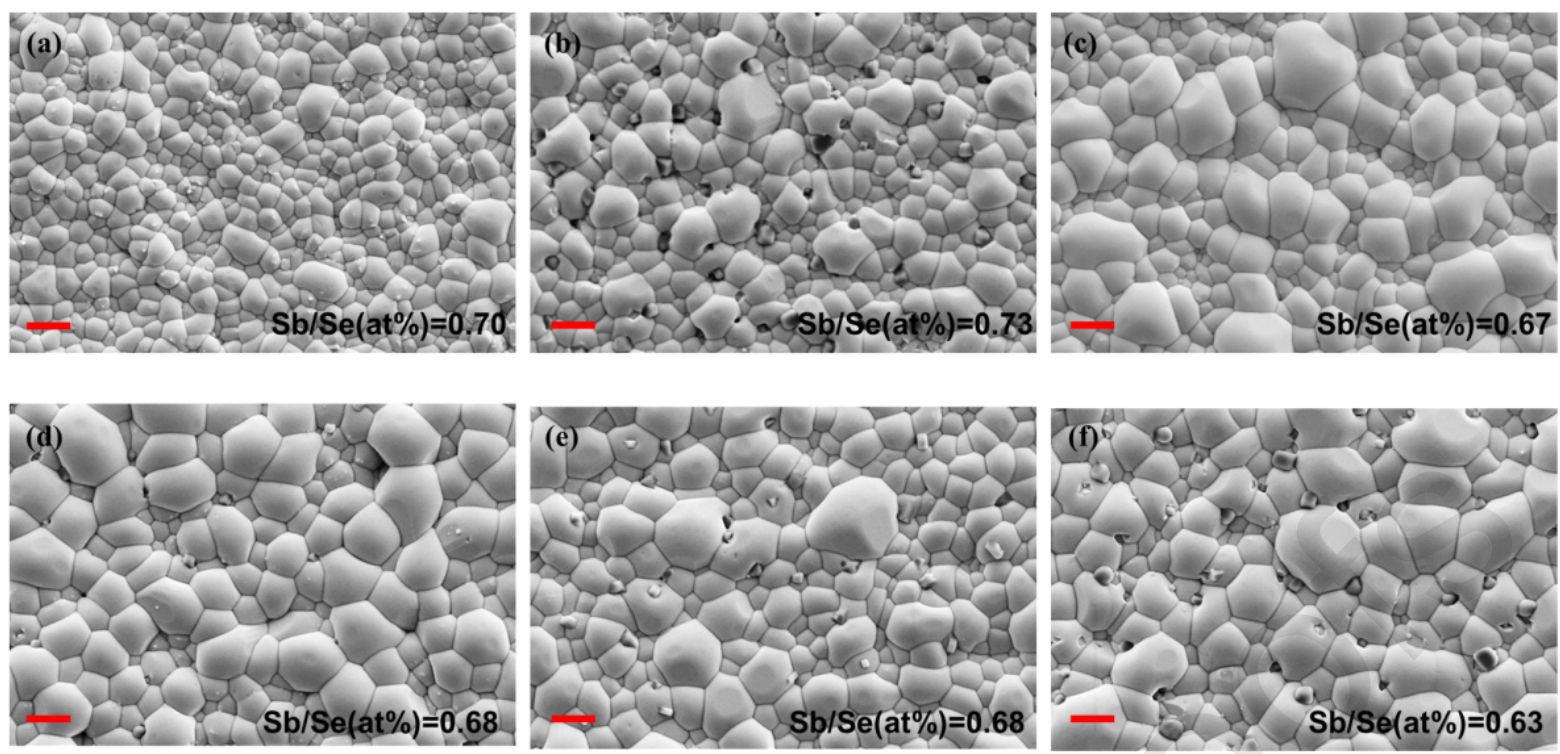

Figure 2. Surface morphologies of the $\mathrm{Sb}_{2} \mathrm{Se}_{3}$ thin films with different selenization durations

SEM top-view images of $\mathrm{Sb}$ metallic precursor selenized at $400{ }^{\circ} \mathrm{C}$ for $5 \mathrm{~min}(\mathrm{a}), 10 \mathrm{~min}$ (b), $15 \min (\mathrm{c}), 20 \mathrm{~min}(\mathrm{~d}), 25 \mathrm{~min}(\mathrm{e})$ and $30 \mathrm{~min}(\mathrm{f})$. The red scale bar at the left bottom corner of each figure reads $1 \mu \mathrm{m}$. 

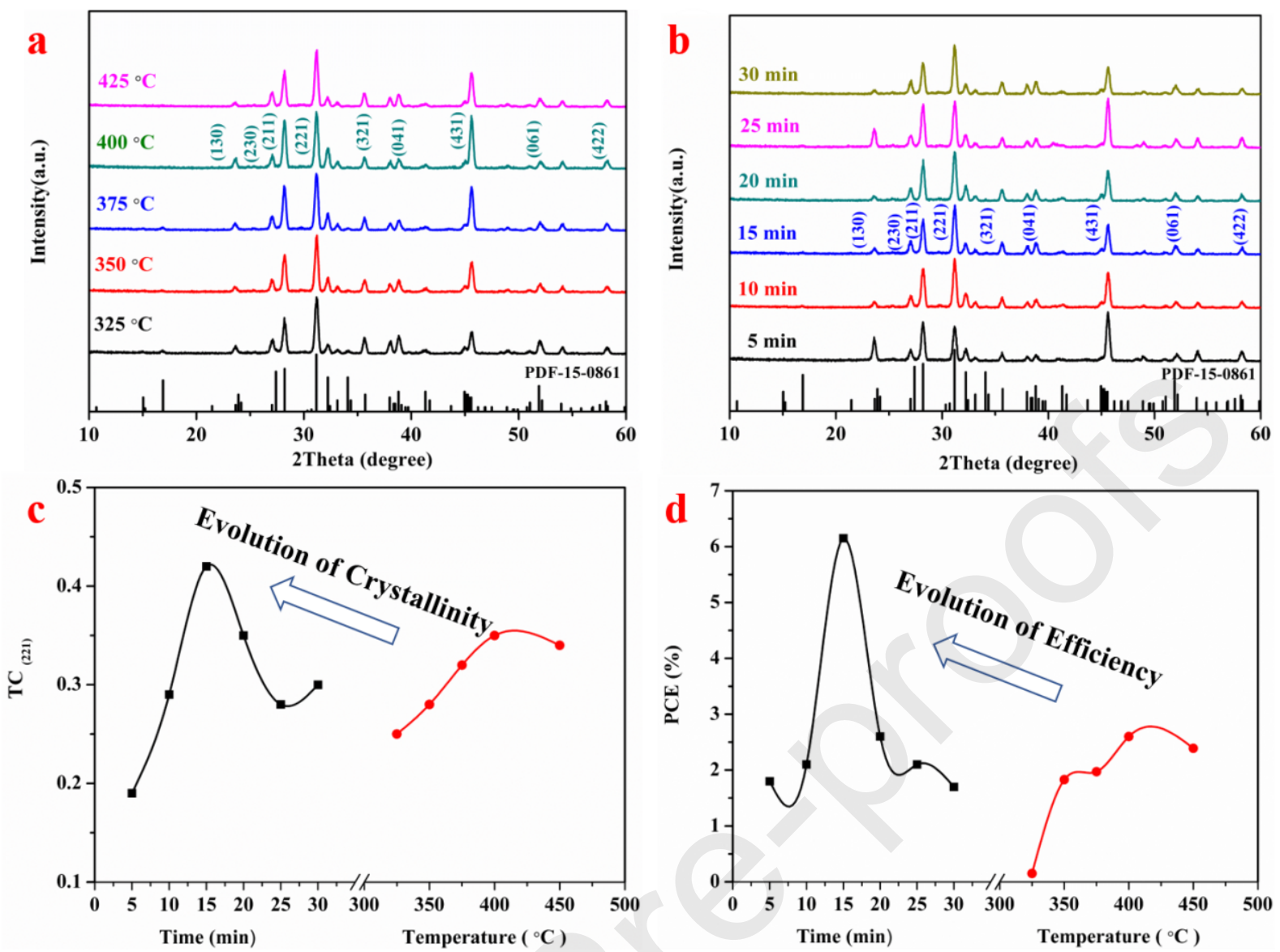

Figure 3. Morphology evolutions of the $\mathrm{Sb}_{2} \mathrm{Se}_{3}$ thin films. XRD data of $\mathrm{Sb}_{2} \mathrm{Se}_{3}$ thin films annealed by using different selenization temperatures (a) and durations (b). Texture coefficients (TC) of (221) diffraction peaks (c) and PCE (d) of the $\mathrm{Sb}_{2} \mathrm{Se}_{3}$ thin film devices fabricated via various selenization scenarios. 

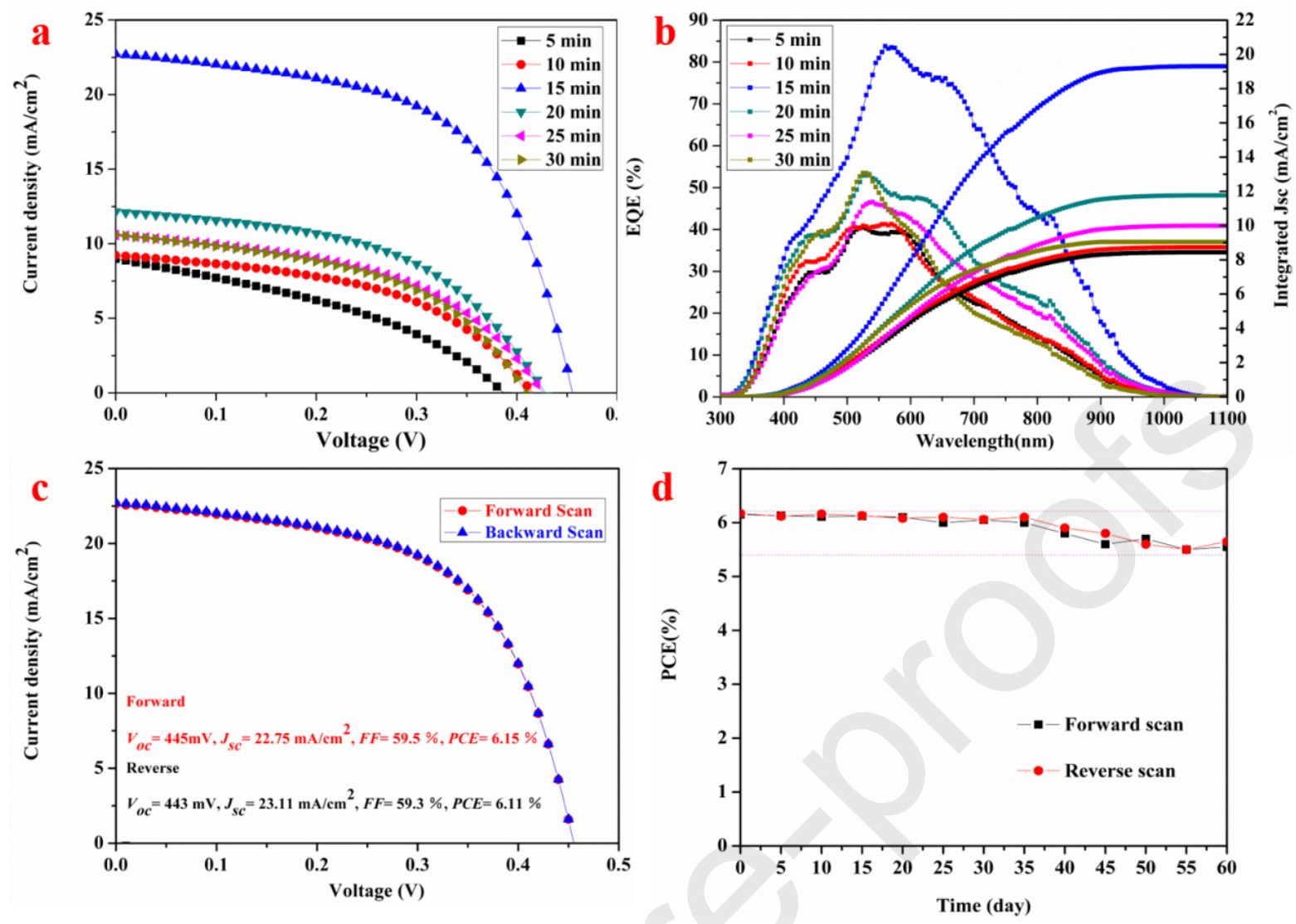

Figure 4. Device performance. Current density-voltage $(J-V)$ curves (a), external quantum efficiency (EQE) and integrated $J_{S C}$ (b) of $\mathrm{Sb}_{2} \mathrm{Se}_{3}$ devices fabricated by using different selenization durations. Current density-voltage $(J-V)$ curves from different scanning directions of the champion device (c). Device stability of the $15 \mathrm{~min}-\mathrm{Sb}_{2} \mathrm{Se}_{3}$ device after $1000 \mathrm{~h}$ storage in air ambient without special treatment/encapsulation (d). 

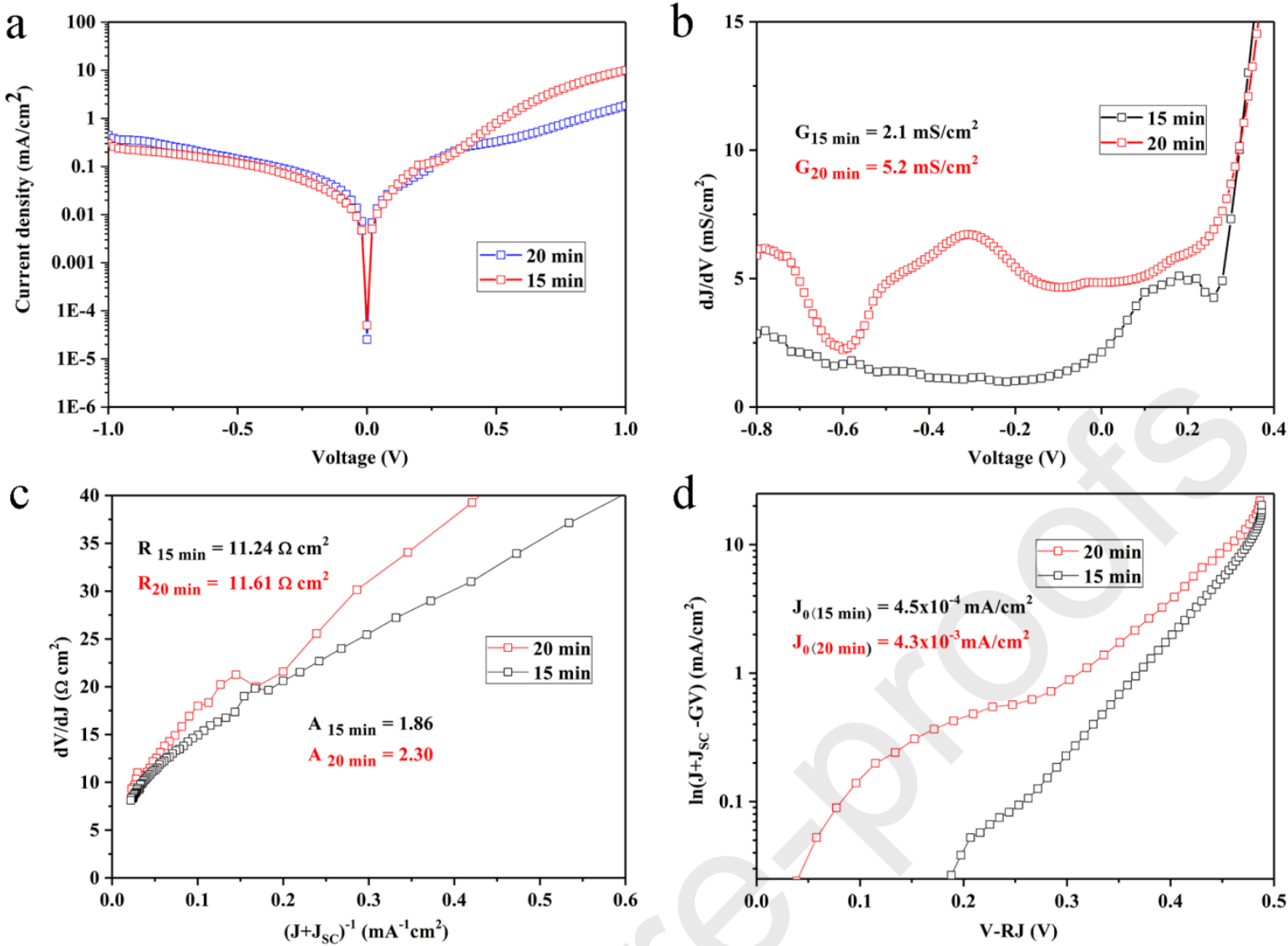

Figure 5. Dark $J-V$ characteristics for the $15 \mathrm{~min}-\mathrm{Sb}_{2} \mathrm{Se}_{3}$ and $20 \mathrm{~min}-\mathrm{Sb}_{2} \mathrm{Se}_{3}$ devices. Dark $J-V$ curves (a), shunt conductance $G$ characterizations (b), series resistance $R$ and ideality factor $A$ characterizations (c) and reverse saturation current density $J_{o}$ characterizations (d) of the two devices. 


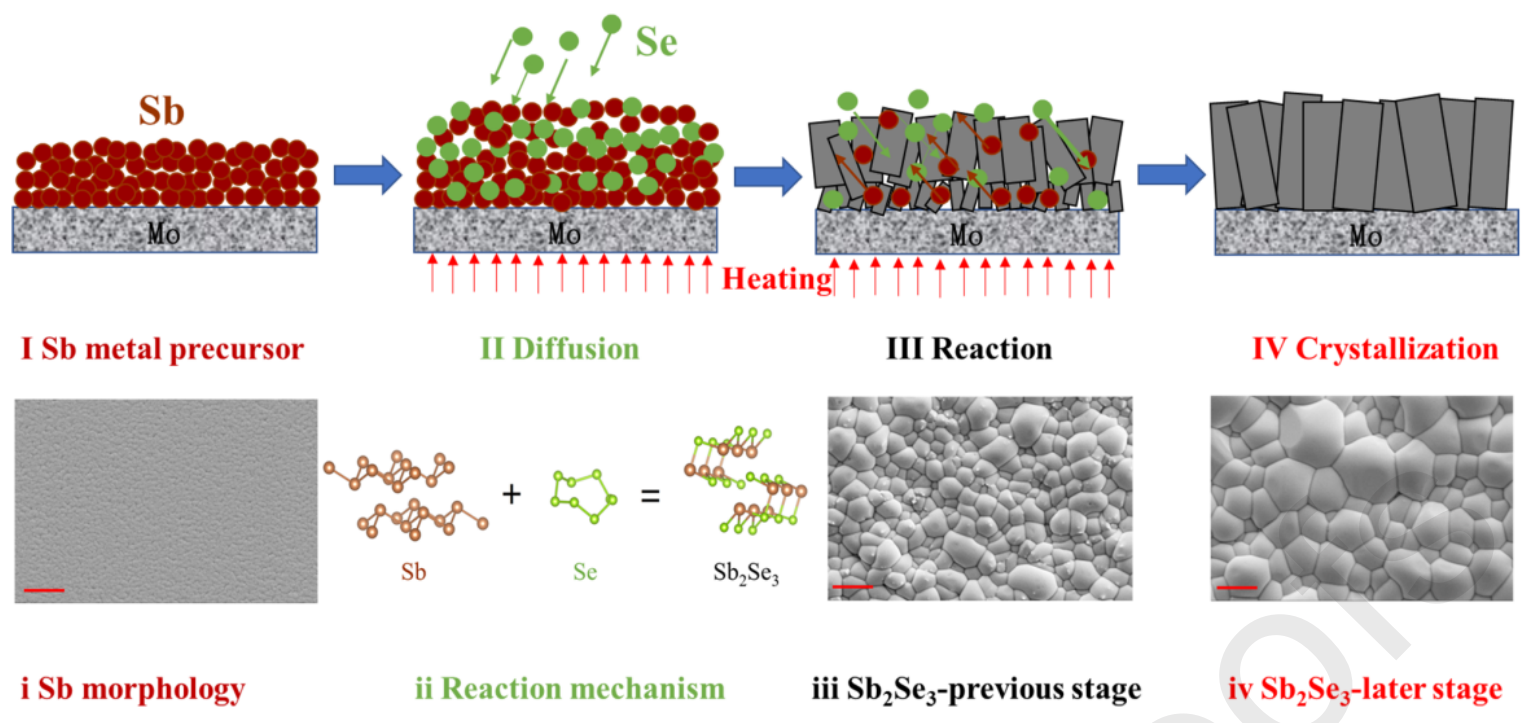

Figure 6. Crystallization procedures of $\mathrm{Sb}_{2} \mathrm{Se}_{3}$ thin films prepared via $\mathrm{Sb}$ metallic precursor selenization. The red scale bar at the left bottom corner of each SEM image reads $1 \mu \mathrm{m}$.
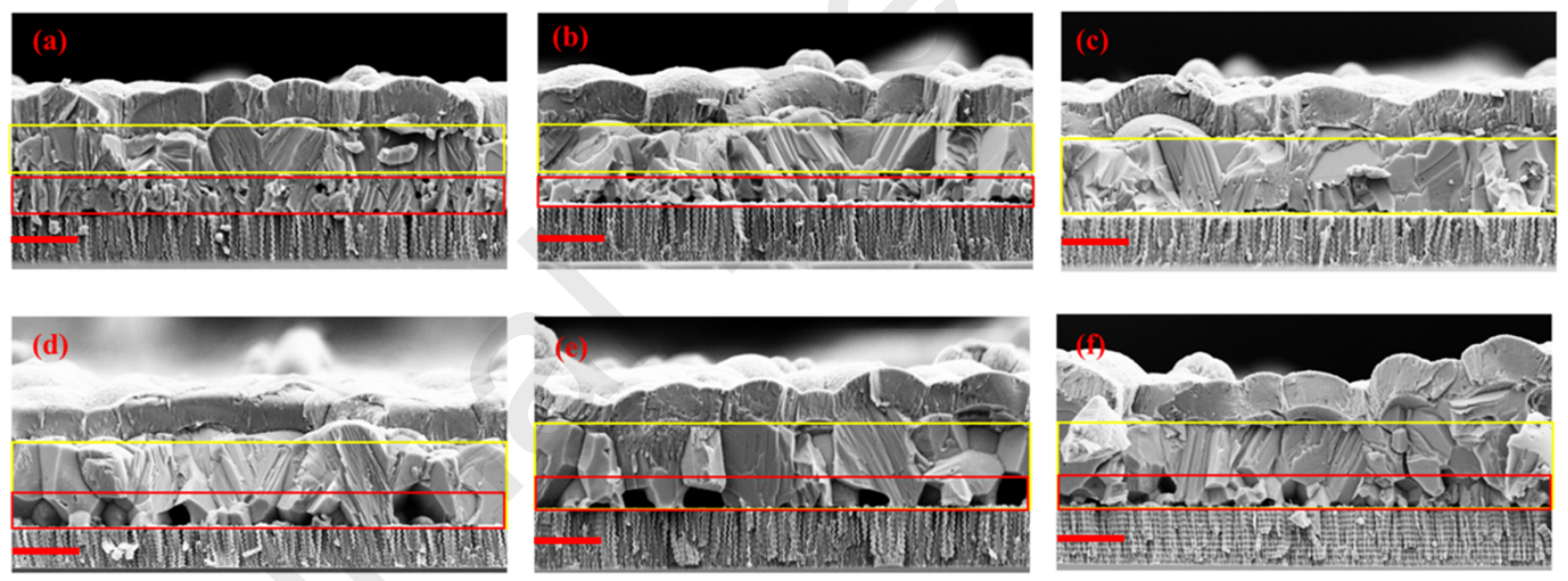

Figure 7. Cross-sectional microstructures of $\mathrm{Sb}_{2} \mathrm{Se}_{3}$ thin films with different selenization durations. SEM cross-sectional images of Sb metallic precursor selenized at $400{ }^{\circ} \mathrm{C}$ for $5 \mathrm{~min}$ (a), $10 \mathrm{~min}(\mathbf{b}), 15 \mathrm{~min}(\mathbf{c}), 20 \mathrm{~min}(\mathbf{d}), 25 \mathrm{~min}(\mathbf{e})$ and $30 \mathrm{~min}(\mathbf{f})$. The red scale bar at the left bottom corner of each figure reads $1 \mu \mathrm{m}$. 

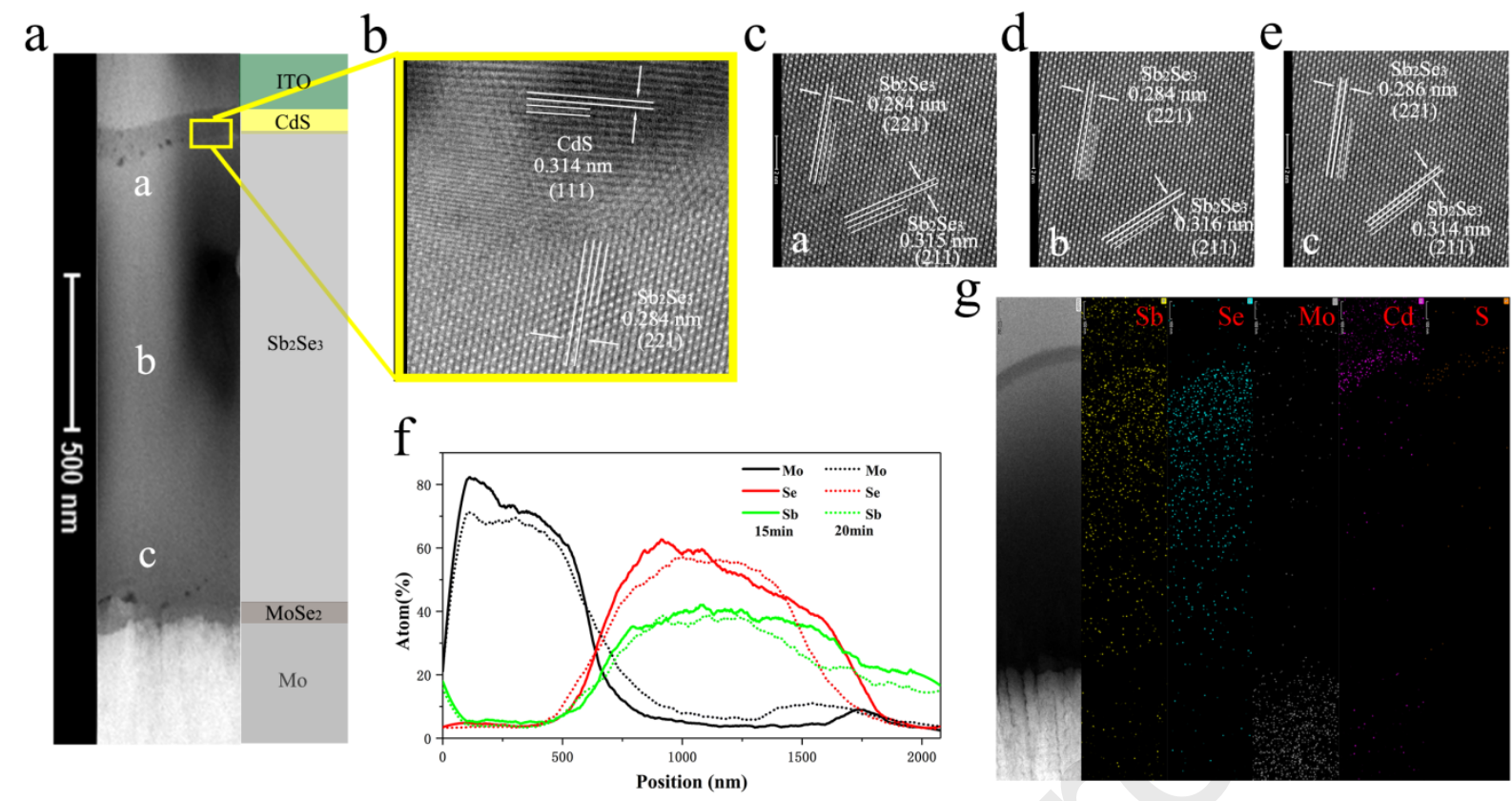

Figure 8. TEM characterization of the $\mathrm{Sb}_{2} \mathrm{Se}_{3}$ champion device. Cross-sectional TEM image of the $\mathrm{Sb}_{2} \mathrm{Se}_{3}$ champion device (a). HRTEM image of the $\mathrm{Sb}_{2} \mathrm{Se}_{3} / \mathrm{CdS}$ interface (b). Lattice fringes of three arbitrary spots $\mathrm{a}, \mathrm{b}$ and $\mathrm{c}$ across the $\mathrm{Sb}_{2} \mathrm{Se}_{3}$ thin film in (a) performed by HRTEM are shown in (c), (d) and (e), correspondingly. EDS elemental profiles across the device (f), HAADF-STEM image and EDS elemental mapping (g) of the device. 

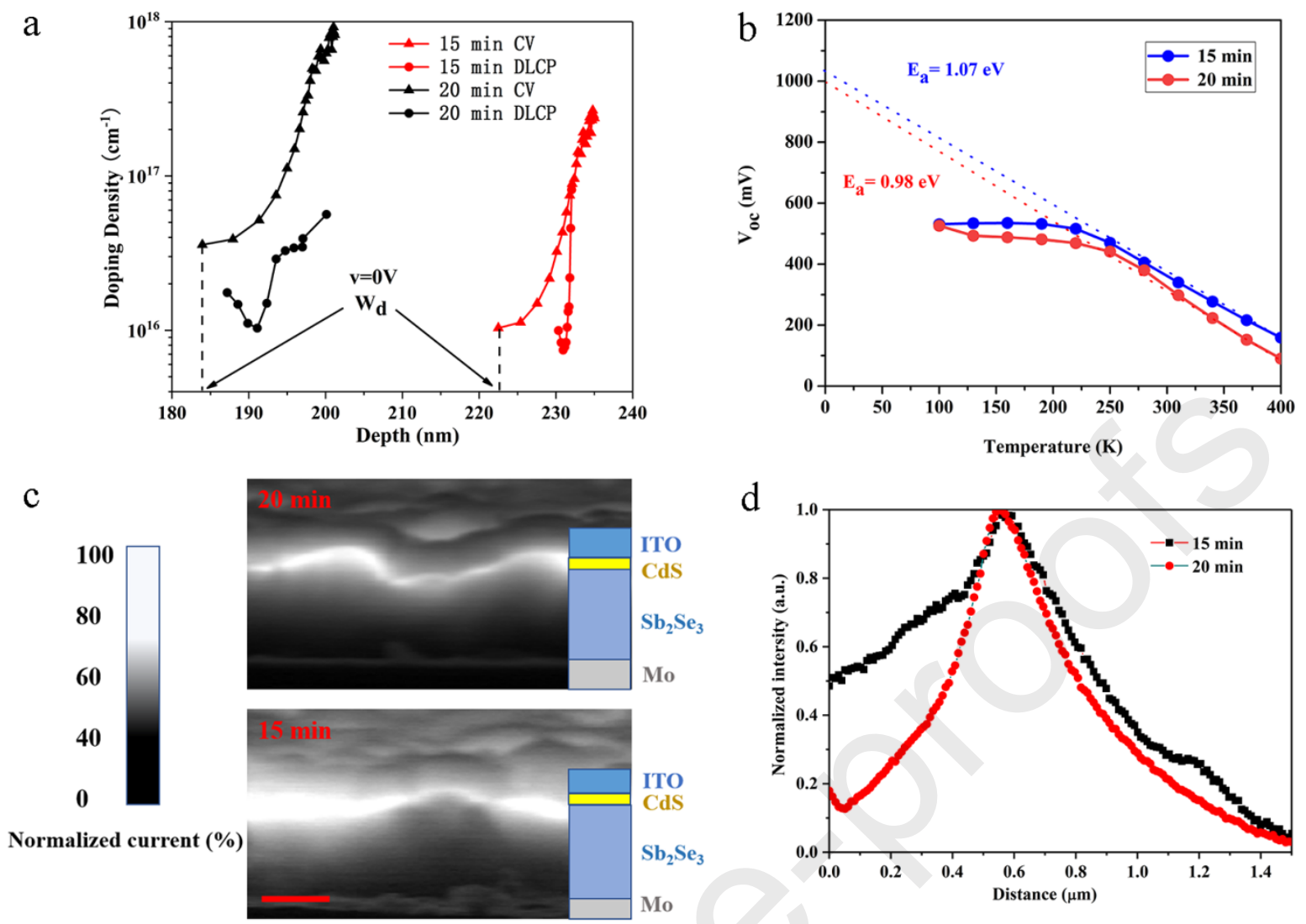

Figure 9. $\mathrm{Sb}_{2} \mathrm{Se}_{3} / \mathrm{CdS}$ interfacial defect characterizations and EBIC analyses of devices. $C V$ and $D L C P$ profiling (a), temperature-dependent open circuit voltage measurements (b), EBIC images (c) and the EBIC signal intensity profiling (d) of the $15 \mathrm{~min}-\mathrm{Sb}_{2} \mathrm{Se}_{3}$ and $20 \mathrm{~min}-\mathrm{Sb}_{2} \mathrm{Se}_{3}$ devices. The red scale bar at the left bottom corner of Figure $9(\mathbf{c})$ reads $1 \mu \mathrm{m}$. 

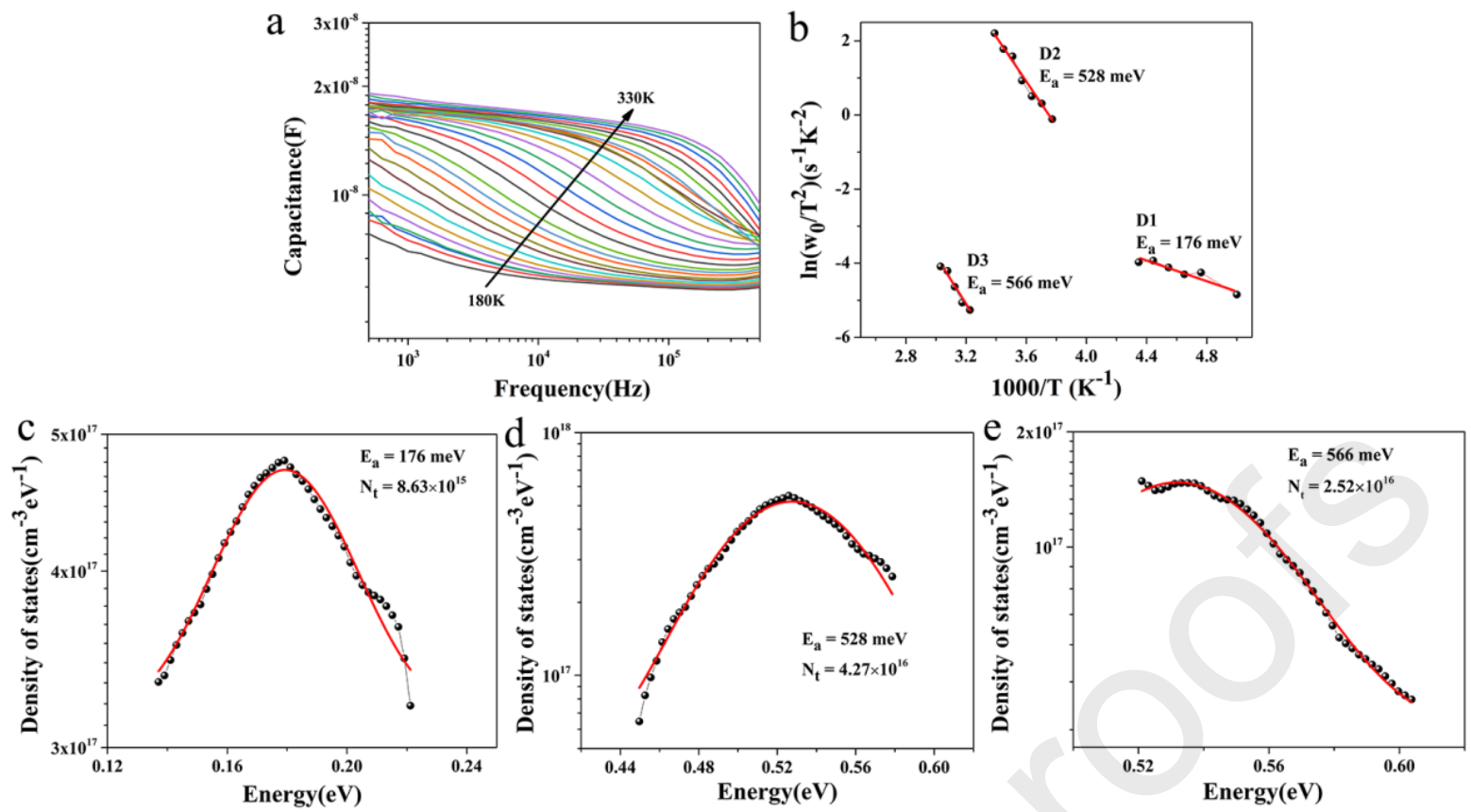

Figure 10. Temperature-dependent admittance analyses of the champion device. Capacitancefrequency-temperature $(C-f-T)$ spectra (a) and defect activation energies (b) of the $15 \mathrm{~min}$ $\mathrm{Sb}_{2} \mathrm{Se}_{3}$ device. Defect distributions of D1 (c), D2 (d) and D3 (e) of the $15 \mathrm{~min}-\mathrm{Sb}_{2} \mathrm{Se}_{3}$ device derived from the admittance spectra. 
Table 1. Device performance parameters of the $\mathrm{Sb}_{2} \mathrm{Se}_{3}$ device with different selenization time

\begin{tabular}{ccccc}
\hline Samples & $\boldsymbol{V}_{\boldsymbol{o c}}(\mathbf{m V})$ & $\boldsymbol{J}_{\boldsymbol{s c}}\left(\mathbf{m A} \mathbf{A} \mathbf{c m}^{\mathbf{2}}\right)$ & $\boldsymbol{F F}(\mathbf{\%})$ & $\boldsymbol{E}_{f f} \mathbf{( \% )}$ \\
\hline 5 min & 390 & 9.00 & 37.0 & 1.32 \\
$10 \mathrm{~min}$ & 420 & 9.23 & 48.0 & 1.84 \\
15 min & 455 & 22.75 & 59.5 & 6.15 \\
20 min & 430 & 12.16 & 49.8 & 2.60 \\
25 min & 430 & 10.6 & 47.5 & 2.16 \\
30 min & 410 & 10.6 & 47.8 & 2.07 \\
\hline
\end{tabular}

Table 2. Summary of planar heterojunction $\mathrm{Sb}_{2} \mathrm{Se}_{3}$ solar cell with substrate configuration publications by different fabrication methods

\begin{tabular}{|c|c|c|c|c|c|c|}
\hline Method & Device configuration & Eff $(\%)$ & $V_{o c}(\mathrm{mV})$ & $J_{a c}\left(\mathrm{~mA} / \mathrm{cm}^{2}\right)$ & $F F(\%)$ & Ref. \\
\hline Co-eva ${ }^{\text {a) }}$ & $\mathrm{Mo} / \mathrm{Sb}_{2} \mathrm{Se}_{3} / \mathrm{CdS} / \mathrm{ZnO} / \mathrm{AZO} / \mathrm{Ag}$ & 4.25 & 427 & 17.11 & 58.15 & Mai [45] \\
\hline $\operatorname{CSS}^{\mathrm{b})}$ & $\mathrm{Mo} / \mathrm{Sb}_{2} \mathrm{Se}_{3} / \mathrm{Cd}_{\mathrm{x}} \mathrm{Zn}_{1-\mathrm{x}} \mathrm{S} / \mathrm{ZnO} / \mathrm{AZO}$ & 6.71 & 403 & 25.69 & 64.78 & Mai [23] \\
\hline Sputc) & $\mathrm{Mo} / \mathrm{Sb}_{2} \mathrm{Se}_{3} / \mathrm{CdS} / \mathrm{ZnO} / \mathrm{AZO} / \mathrm{Ag}$ & 3.35 & 437 & 15.93 & 48 & Liang [21] \\
\hline Sput-Sed) & $\mathrm{Mo} / \mathrm{Sb}_{2} \mathrm{Se}_{3} / \mathrm{CdS} / \mathrm{ITO} / \mathrm{Ag}$ & 6.06 & 494 & 25.91 & 47.7 & Liang [27] \\
\hline Sput-Sb-Se (RTP) e) & $\mathrm{Mo} / \mathrm{Sb}_{2} \mathrm{Se}_{3} / \mathrm{CdS} / \mathrm{ZnO} / \mathrm{AZO} / \mathrm{Al}$ & 3.47 & 414 & 16.0 & 52 & Zhu [5] \\
\hline Sput-Sb-Se (NTP) $)^{\mathrm{f}}$ & $\mathrm{Mo} / \mathrm{Sb}_{2} \mathrm{Se}_{3} / \mathrm{CdS} / \mathrm{ITO} / \mathrm{Ag}$ & 6.15 & 455 & 22.75 & 59.5 & This work \\
\hline
\end{tabular}

a) Co-evaporation. ${ }^{\text {b) }}$ Closed space sublimation. ${ }^{\text {c) }}$ Sputtering $\mathrm{Sb}_{2} \mathrm{Se}_{3}$. ${ }^{\text {d) }}$ Sputtering $\mathrm{Sb}_{2} \mathrm{Se}_{3}$ and post-selenization. ${ }^{\text {e) }} \mathrm{Sputtering} \mathrm{Sb}$ and post-selenization with Rapid Thermal Process. d) Sputtering Sb and post-selenization with Normal Thermal Process.

Table 3. Defect parameters of the $15 \mathrm{~min}-\mathrm{Sb}_{2} \mathrm{Se}_{3}$ and $20 \mathrm{~min}-\mathrm{Sb}_{2} \mathrm{Se}_{3}$ devices characterized by admittance spectroscopy

\begin{tabular}{|c|c|c|c|c|c|c|}
\hline & \multicolumn{2}{|c|}{ D1 } & \multicolumn{2}{|c|}{ D2 } & \multicolumn{2}{|c|}{ D3 } \\
\hline & $E_{a}(\mathrm{meV})$ & $N_{t}\left(\mathrm{~cm}^{-3}\right)$ & $E_{a}(\mathrm{meV})$ & $N_{t}\left(\mathrm{~cm}^{-3}\right)$ & $E_{a}(\mathrm{meV})$ & $N_{t}\left(\mathrm{~cm}^{-3}\right)$ \\
\hline $15 \mathrm{~min}-\mathrm{Sb}_{2} \mathrm{Se}_{3}$ & 176 & $8.6 \times 10^{15}$ & 528 & $4.3 \times 10^{16}$ & 566 & $2.5 \times 10^{16}$ \\
\hline $20 \mathrm{~min}-\mathrm{Sb}_{2} \mathrm{Se}_{3}$ & 181 & $1.1 \times 10^{16}$ & 496 & $3.6 \times 10^{16}$ & 593 & $2.3 \times 10^{17}$ \\
\hline
\end{tabular}


Table of contents: An effective combination reaction involved with sputtered and selenized $\mathrm{Sb}$ precursor was used for preparing $\mathrm{Sb}_{2} \mathrm{Se}_{3}$ thin film solar cells. Self-assembled growth of $\mathrm{Sb}_{2} \mathrm{Se}_{3}$ with large crystal grains, benign orientation, stoichiometric composition and highquality heterojunction interface. A champion device with PCE of $6.15 \%$ is comparable to the state-of-the-art devices and represents the highest efficiency of sputtered $\mathrm{Sb}_{2} \mathrm{Se}_{3}$ solar cells.

ToC figure
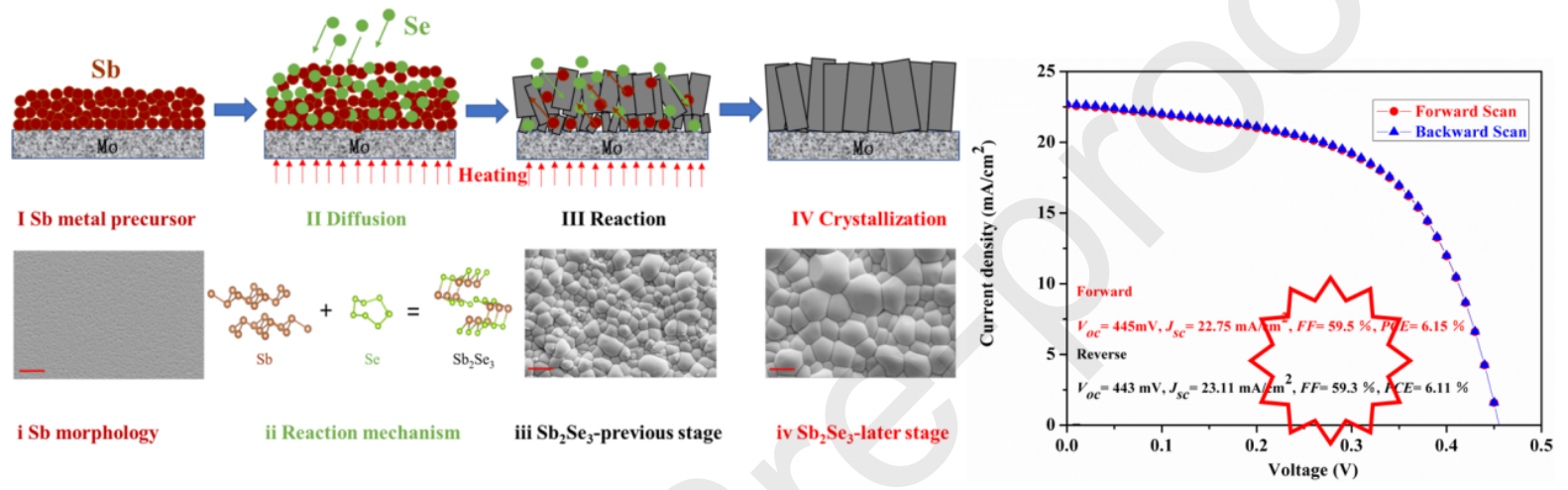

An effective combination reaction of sputtered and selenized $\mathrm{Sb}$ with high $\mathrm{FF} \mathrm{Sb}_{2} \mathrm{Se}_{3}$ solar cells 
Supporting Information

\section{An effective combination reaction involved with sputtered and}

\section{selenized $\mathrm{Sb}$ precursors for efficient $\mathrm{Sb}_{2} \mathrm{Se}_{3}$ thin film solar cells}

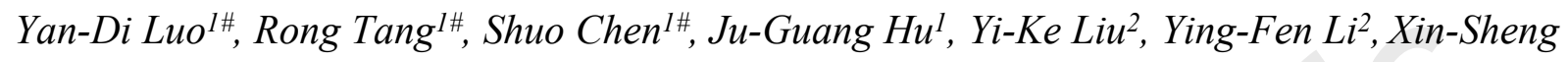
Liu $^{3}$, Zhuang-Hao Zheng ${ }^{1}$, Zheng-Hua Su${ }^{1}$, Xiu-Fang Ma ${ }^{1}$, Ping Fan ${ }^{1}$, Xiang-Hua Zhang 4 , Hong-Li Ma ${ }^{4}$,Zhi-Gang Chen ${ }^{5}$, Guang-Xing Liang ${ }^{1 *}$
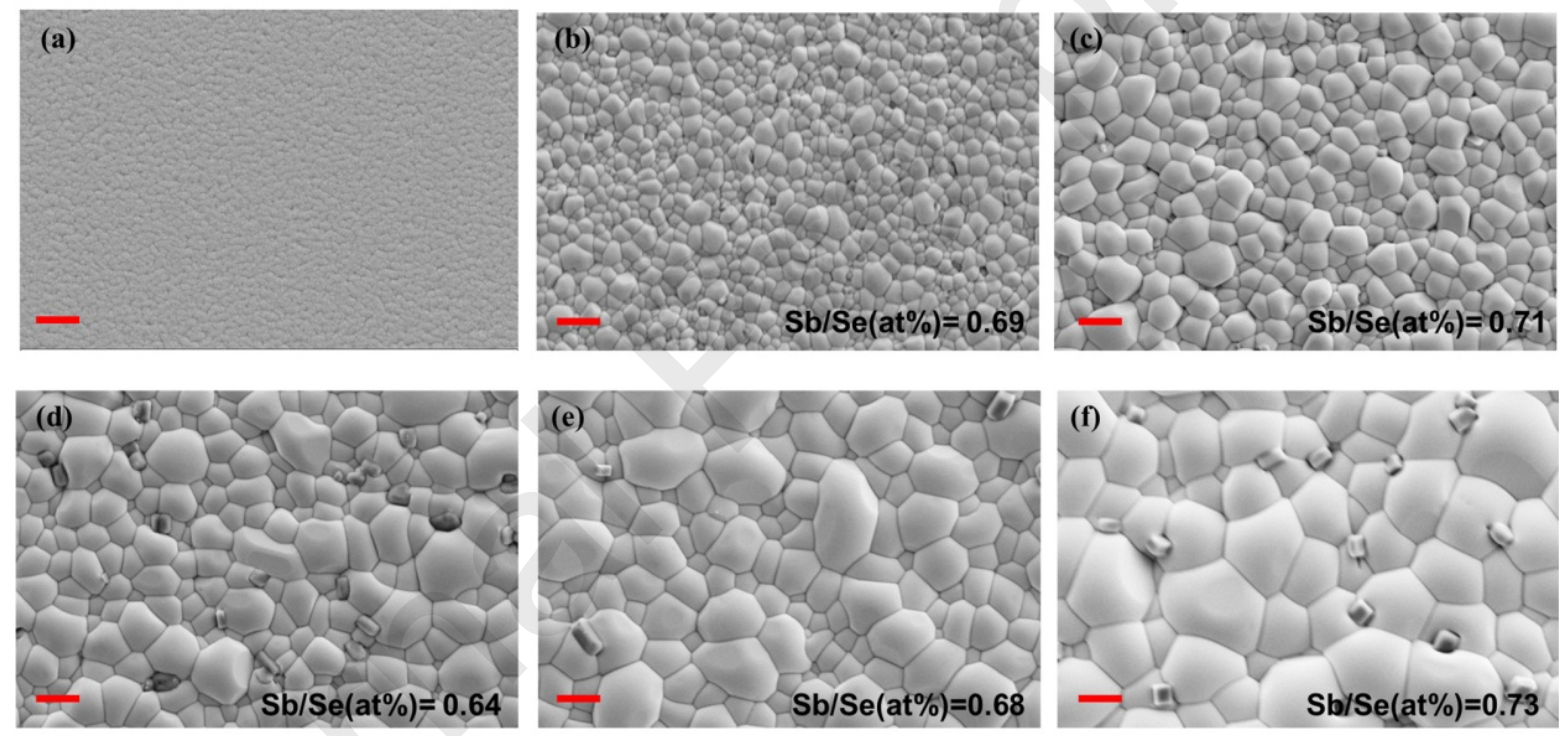

Figure S1. Surface morphologies of the $\mathrm{Sb}_{2} \mathrm{Se}_{3}$ thin films with different selenization temperatures. SEM top-view images of Sb metallic precursor (a), and selenized at $325{ }^{\circ} \mathrm{C}(\mathbf{b})$, $350{ }^{\circ} \mathrm{C}(\mathbf{c}), 375^{\circ} \mathrm{C}(\mathbf{d}), 400{ }^{\circ} \mathrm{C}(\mathbf{e})$ and $425^{\circ} \mathrm{C}(\mathbf{f})$. The red scale bar at the left bottom corner of each figure reads $1 \mu \mathrm{m}$. 


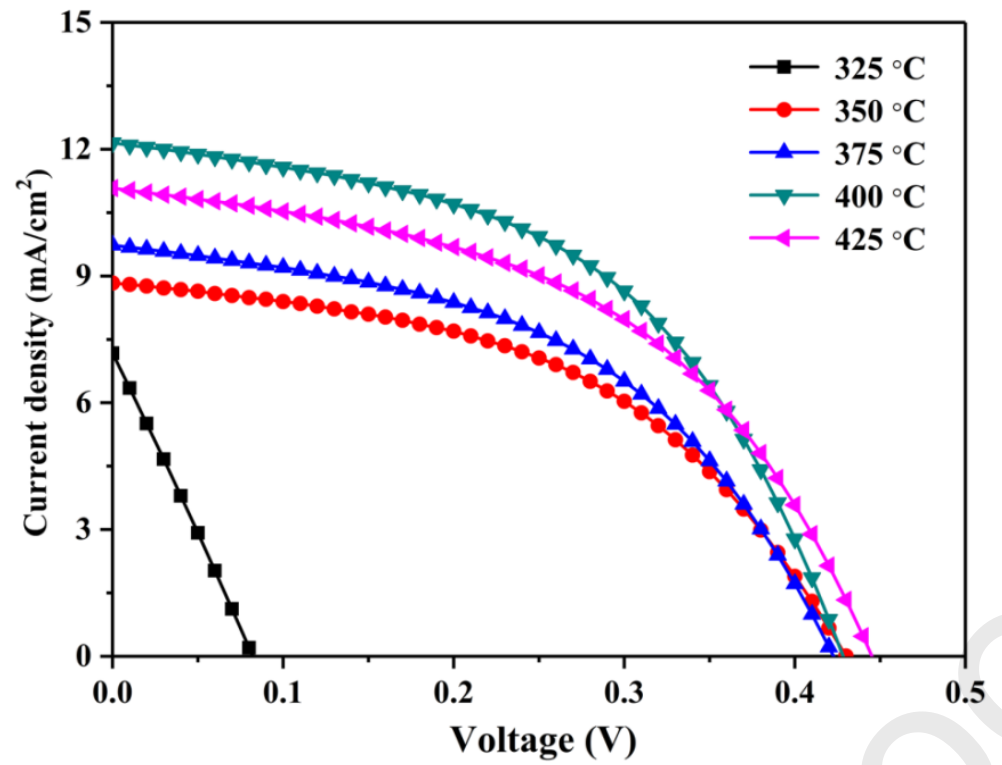

Figure S2. Current density-voltage $(J-V)$ curves of $\mathrm{Sb}_{2} \mathrm{Se}_{3}$ devices fabricated at different selenization temperatures.
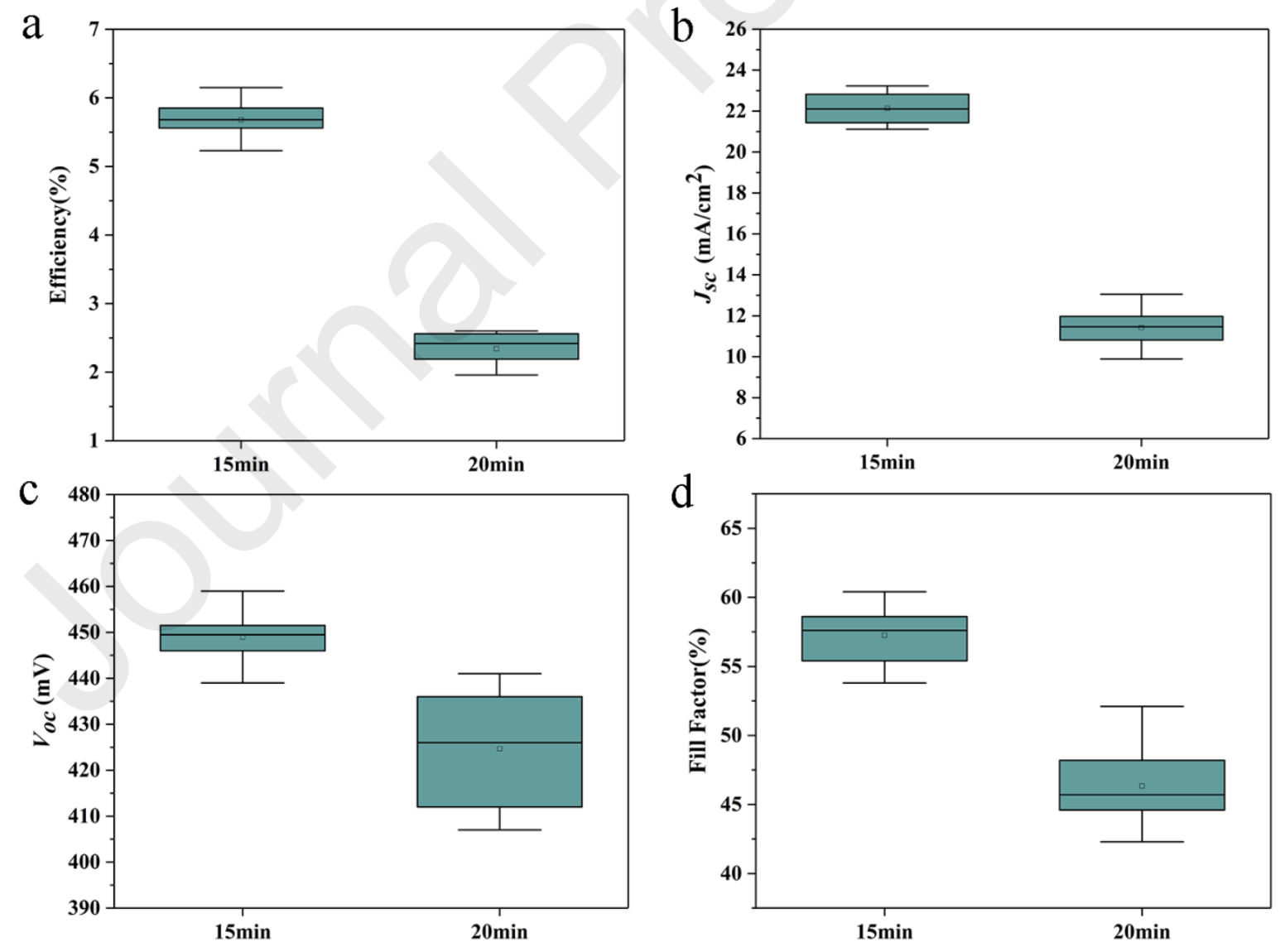

Figure S3. Main parameters of the $15-\mathrm{Sb}_{2} \mathrm{Se}_{3}$ and $20-\mathrm{Sb}_{2} \mathrm{Se}_{3}$ devices 

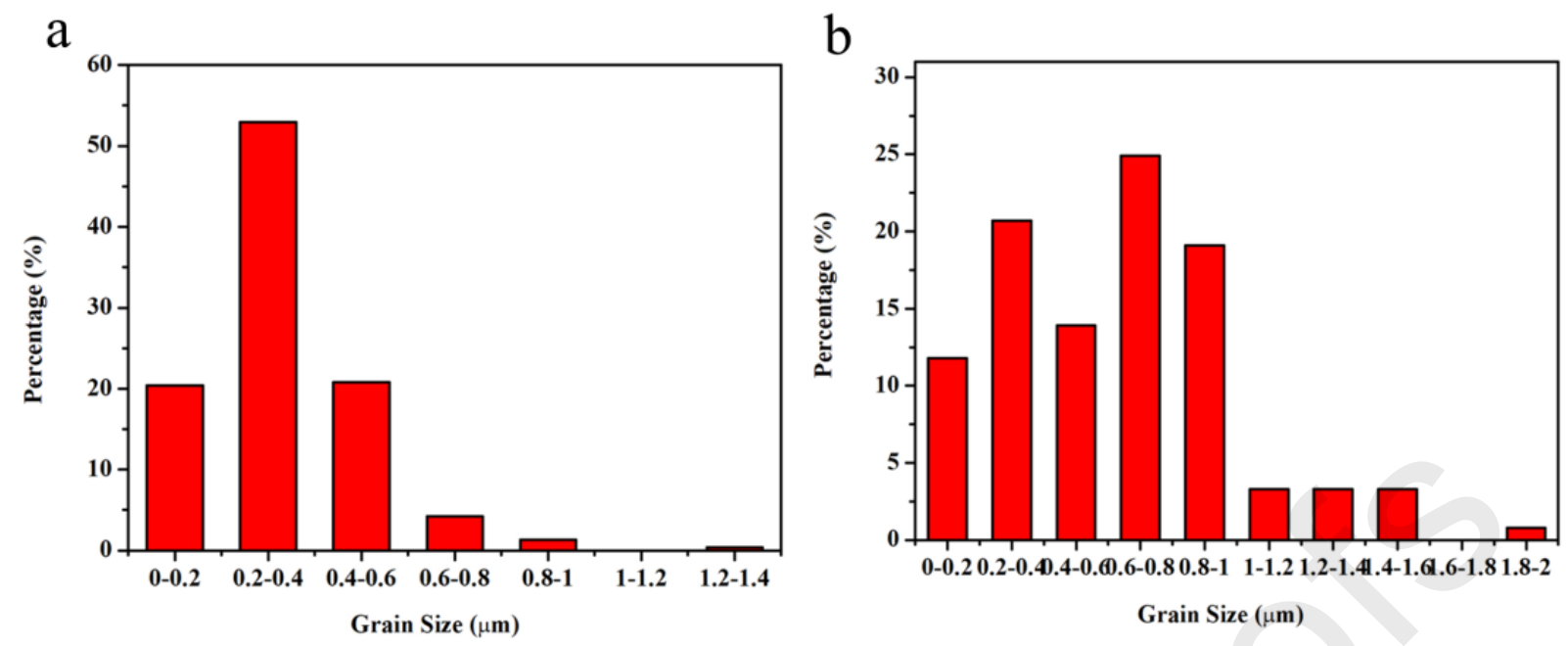

Figure S4. Grain size distributions of $\mathrm{Sb}_{2} \mathrm{Se}_{3}$ thin films at the early stage (a) and later stage (b) of selenization.

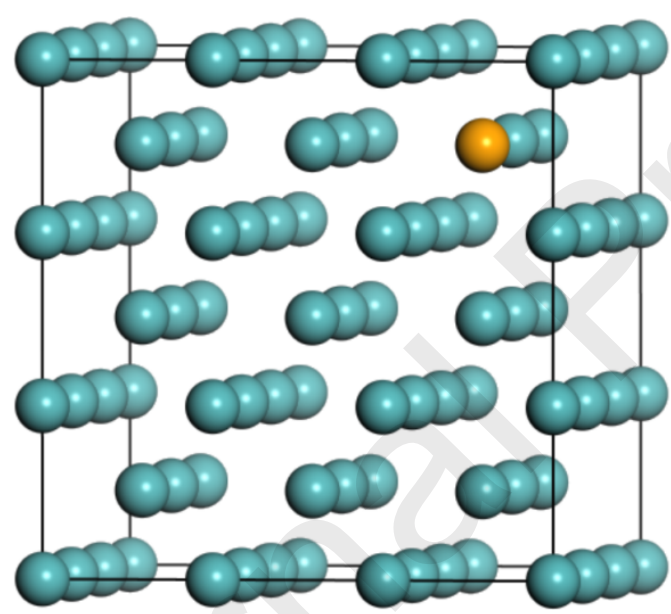

(a) $-2.54 \mathrm{eV}$

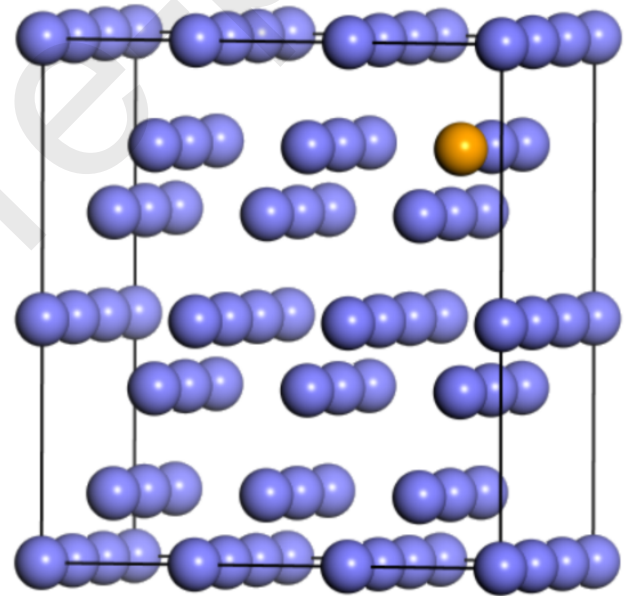

(b) $-1.23 \mathrm{eV}$

Figure S5. The schematic structures of bulk Mo (a) and Sb (b) system, in which 1/54 bulk atoms were substituted by Se atoms. The black line denotes the periodic supercell used in DFT calculations, and the corresponding energy change due to the substitution by Se was listed below. The green, orange and purple balls represent $\mathrm{Mo}$, Se and $\mathrm{Sb}$ atoms, respectively. 
Table S1. Device performance parameters of the $\mathrm{Sb}_{2} \mathrm{Se}_{3}$ devices with different selenization temperatures

\begin{tabular}{lllll}
\hline Samples & $V_{o c}(\mathrm{mV})$ & $J_{s c}\left(\mathrm{~mA} / \mathrm{cm}^{2}\right)$ & $F F(\%)$ & $E_{f f}(\%)$ \\
\hline $325^{\circ} \mathrm{C}$ & 80 & 7.18 & 27.0 & 0.15 \\
$350^{\circ} \mathrm{C}$ & 430 & 8.84 & 48.0 & 1.83 \\
$375^{\circ} \mathrm{C}$ & 420 & 9.74 & 48.2 & 1.97 \\
$400^{\circ} \mathrm{C}$ & 430 & 12.16 & 49.8 & 2.60 \\
$425^{\circ} \mathrm{C}$ & 450 & 11.08 & 48.0 & 2.39 \\
\hline
\end{tabular}

\section{Declaration of interests}

$\bigotimes$ The authors declare that they have no known competing financial interests or personal relationships that could have appeared to influence the work reported in this paper.

$\square$ The authors declare the following financial interests/personal relationships which may be considered as potential competing interests:

$\diamond \quad$ An effective combination reaction of $\mathrm{Sb}$ metallic precursors for efficient $\mathrm{Sb}_{2} \mathrm{Se}_{3}$ solar cell

$\diamond$ Self-assembled growth of stoichiometric $\mathrm{Sb}_{2} \mathrm{Se}_{3}$ thin film with desired orientation

$\diamond \quad$ An over-thick $\mathrm{MoSe}_{2}$ interfacial layer could be effectively suppressed

$\diamond$ The highest PCE of $6.15 \%$ in sputtered $\mathrm{Sb}_{2} \mathrm{Se}_{3}$ thin film solar cell with excellent stability 

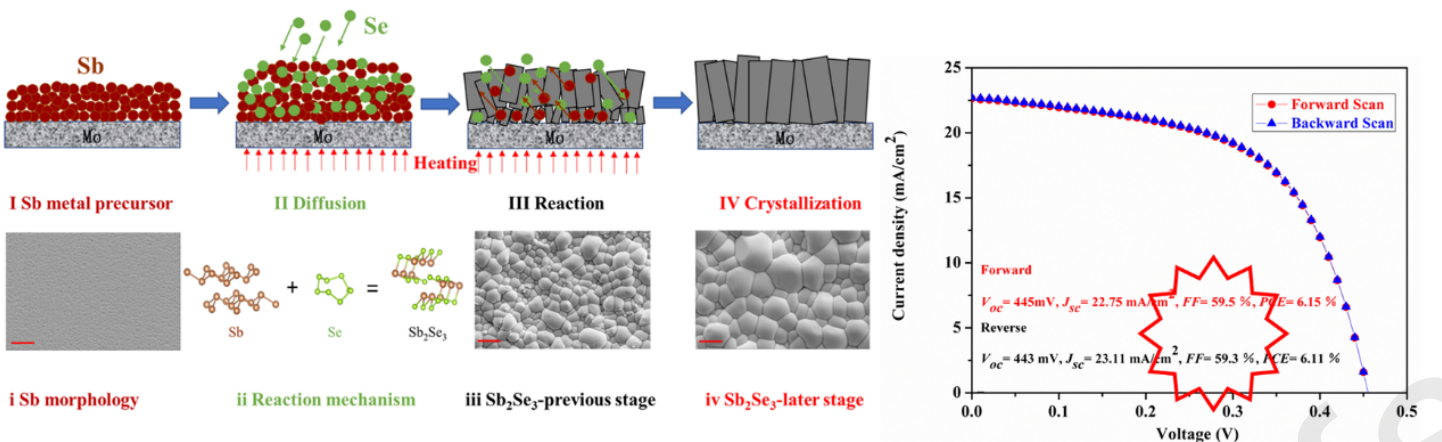

An effective combination reaction of sputtered and selenized $\mathrm{Sb}$ with high $\mathrm{FF} \mathrm{Sb}_{2} \mathrm{Se}_{3}$ solar cells 